
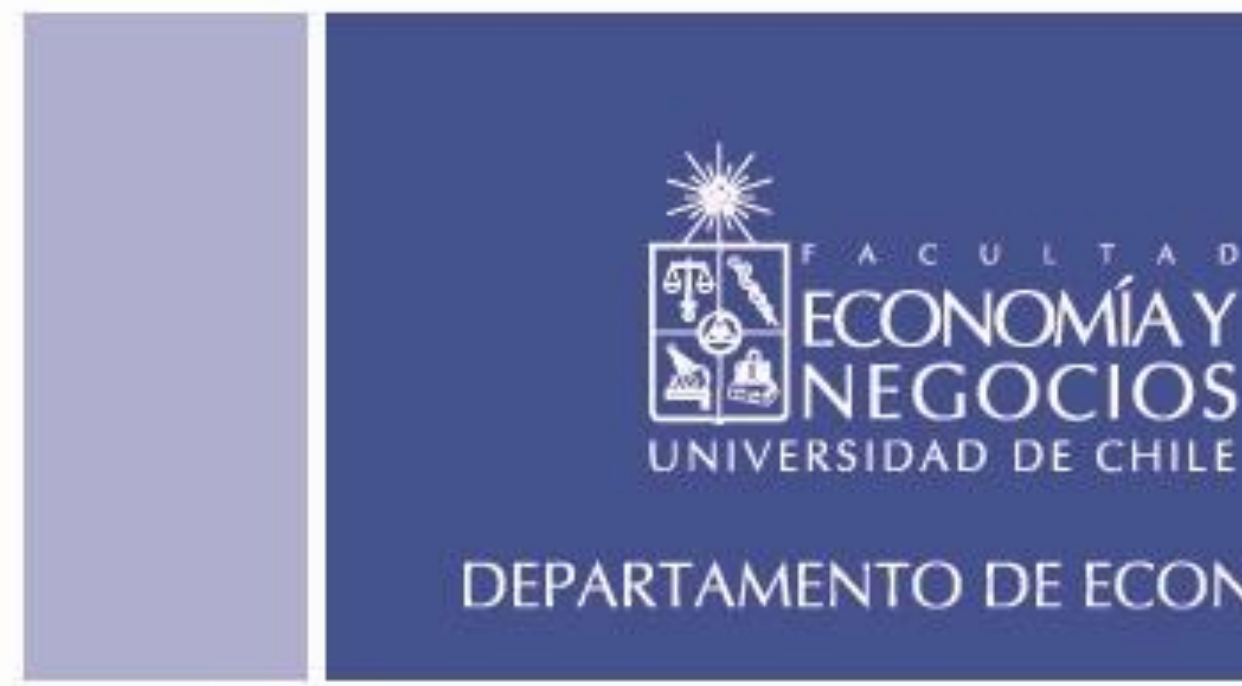

DEPARTAMENTO DE ECONOMÍA

\title{
THE IMPACT OF NATIONAL RESEARCH FUNDS: A REGRESSION DISCONTINUITY APPROACH TO THE CHILEAN FONDECYT
}

Autores: José Miguel Benavente, Gustavo Crespi, Lucas Figal Garone y Alessandro Maffioli

Santiago, Abril de 2012

La serie de Documentos de Trabajo (SDT) del Departamento de Economía de la Universidad de Chile en versión PDF puede descargarse en la dirección electrónica www.econ.uchile.cl/SDT . Para contactar al editor ejecutivo de SDT remitirse a sdt@econ.uchile.cl 


\title{
The Impact of National Research Funds:
}

\section{A Regression Discontinuity Approach to the Chilean FONDECYT}

\author{
José Miguel Benavente \\ Universidad Adolfo Ibáñez \\ Gustavo Crespi \\ Inter-American Development Bank \\ Lucas Figal Garone \\ Inter-American Development Bank and Universidad de San Andrés \\ Alessandro Maffioli * \\ Inter-American Development Bank
}

March 2012

\begin{abstract}
This paper analyzes the role of National Research Funds in promoting scientific production in emerging economies. The study focuses on the impact of the Chilean National Science and Technology Research Fund (FONDECYT). The analysis uses data drawn from international sources of bibliometric information combined with the administrative records of the program's executing unit. To measure the program's impact, we implement a Regression Discontinuity (RD) design on principal researchers who applied for funding between 1988 and 1997 considering as outcomes both quantity (publications up to 2002) and quality (citations up to 2005) of their scientific production. Our results show significant and positive impact in terms of publications, but no impact in terms of quality of scientific production in the proximity of the program's threshold ranking.
\end{abstract}

JEL CODES: O30, O38

Keywords: FONDECYT, Chile, Economics of Science, Scientific Grants, Regressiondiscontinuity Design, Policy Evaluation.

* José Miguel Benavente, Business School, Universidad de Adolfo Ibáñez, Santiago, Chile. jmbenavente@uai.cl. Gustavo Crespi, Competitiveness and Innovation Division, Inter-American Development Bank, Washington D.C. gcrespi@iadb.org. Lucas Figal Garone, Strategy Development Division, Inter-American Development Bank, Washington D.C. and Universidad de San Andres, Victoria, Buenos Aires, Argentina 1figal@iadb.org. Alessandro Maffioli, Strategy Development Division, InterAmerican Development Bank, Washington D.C. alessandrom@iadb.org. We are grateful to Roberto Iunes, Inder Ruprah, Yuri Soares, Diego Ubfal and Gonzalo Vázquez Baré for useful discussions and comments. We also thank four anonymous referees for their helpful suggestions and comments. Benavente wants to thank Nucleo Milenio Initiative NS100017 "Intelis Centre" for their partial funding. The findings and interpretation of the authors do not necessarily represent the views of Inter-American Development Bank. The usual disclaimer applies. 


\section{Introduction}

Academics and policy makers have increasingly recognized the importance of scientific research in providing the foundations for both innovation and competitiveness. This recognition has been matched by an increasing amount of public funding for such research by governments and international donors. However, there is a persistent lack of evidence that these investments lead to greater scientific output and, ultimately, to better economic performance. In fact, while much of the available literature concentrates on measuring and describing the results of different types of science policies in terms of scientific outputs, evidence on the causal relationship between the budgets spent on science and scientific outputs is still scarce. ${ }^{1}$ This lack originates not only from the dynamic nature of scientific research, which involves recursive feedbacks between inputs and outputs, but also from practical requirements, which involves defining counterfactuals and gaining access to data on groups of beneficiaries and control groups of non-beneficiaries. ${ }^{2}$ These practical requirements are probably the main reason why experimental and quasi-experimental designs are not common in science policy.

The scientific process results in several research outputs that can be classified into three broadly defined categories: (1) new knowledge, (2) highly qualified human resources, and (3) new technologies. Although there are no direct measures of these types of research outputs, several proxies have been used in previous studies, among them publications, citations and numbers of $\mathrm{PhD}$ degrees awarded. This paper focuses on the causal effect that one specific policy intervention such as a national competitive research fund has on the creation of new knowledge - the first type of output - using a quasi-experimental design. On the basis of bibliometric data and implementing a Regression Discontinuity (RD) approach we want to answer the following research questions:

(i) Does a national competitive research fund increase the amount of scientific production in an emerging country?

(ii) Does a national competitive research fund improve the quality of scientific production?

To explore the above questions, we evaluate the impact of the Chilean National Science and Technology Research Fund (FONDECYT). In addition to shedding some light on the effectiveness of this policy instrument, we aim at contributing to the existing literature also from methodological point of view, showing how a rigorous quasiexperimental evaluation can be implemented and discussing the type of data required for this purpose. Through our analysis, we are able to generate consistent and robust results that show significant and positive impact on quantity of publications (i.e., quantity of scientific production), but no impact on quality of the research.

The rest of the paper is organized as follows. After this brief introduction, section 2 provides some information on the Chilean innovation policy and on the FONDECYT

\footnotetext{
${ }^{1}$ Examples of recent impact evaluations of funding of scientific activity are Chudnovsky et al. (2008), Jacob and Lefgren (2011a, 2011b) and Ubfal and Maffioli (2011).

${ }^{2}$ In this framework, the control group usually refers to researchers that do not receive the program's funding.
} 
institutional setting. Section 3 presents our theoretical framework. Section 4 discusses the evaluation strategy, data source and preparation, and the econometric model. Section 5 discusses the main findings of the program's impact evaluation. Finally, section 6 concludes and identifies potential extensions of this research.

\section{The Chilean Innovation Policy and FONDECYT's Institutional Setting}

In Chile, as in many other countries of Latin America, the institutional setting for Science and Technology (S\&T) has been historically based on a network of universities and technological institutes supported and controlled by the public sector. Indeed, since the mid-19th century, universities provided the main network for basic research and the nuclei for most of the applied research conducted in the country (Benavente and Crespi, 1996). Later on, during the 20th century, a network of technological institutes was created by the State with the aim of supporting the industrialization process and to increase productivity of the natural resource base (in particular in the agriculture, forestry and mining sectors). In addition to this, most of the technological activities developed in the productive sectors were carried-out by a set of publicly owned enterprises established after WWII. The National Development Agency (CORFO), established in 1939 played a pivotal role in the coordination and financing of the overall industrialization process, including technological development. To support this process, the National Science and Technology Research Council (CONICYT) was established in 1967, under the Ministry of Education, with the aim of supporting human capital formation and strengthening the science and technology base of the country.

The process of economic reforms of mid-70s led to increased participation of the private sector in many strategic industries (with the exception of copper mining), to a reduction in the public funding available to the previously created technological institutes and to a dramatic change in the way public resources for S\&T were allocated, moving from direct transfers of budget appropriations to competitive mechanisms. The National Science and Technology Research Fund (FONDECYT), established in 1982 under CONICYT, was a clear manifestation of these changes. Indeed, FONDECYT's main objective is "to maintain, strengthen and use of the national capacity for high-quality research" through supporting individual and collective research initiatives of national researchers and financing them on a quality and excellence basis.

It is important to say that despite the changes, the actual implementation of science policy during the military government (1973-1989) followed a supply oriented approach in which the orientation of the efforts was still determined by the public sector and the academic community. This approach was clearly inspired by the linear model under which it was assumed that knowledge was a sort of public good that once produced by science and technology organizations would automatically flow towards the productive sector. This approach transpires to the design of FONDECYT which is a horizontal fund that support mostly "curiosity driven" research.

With the arrival of the democratic governments, since early 90s a new vision on the importance of the science, technology and innovation for development started to emerge. This vision in addition to recognizing the importance that technological change and innovation play for long term economic growth, also located the firm at the core of the innovation process. So, a major process of institutional construction took place, first 
through the launching of a series national programs ${ }^{3}$ and then through the establishment of a National Council for Innovation and Competitiveness and the approval of a long term science, technology and innovation strategy. ${ }^{4}$

Along this process of institutional development a major shift in science, technology and innovation policies took place putting a stronger emphasis on market incentives, designing interventions that focused on the demand side of the innovation process - the firm - and on fostering the linkages among the different actors in the system. New funding mechanisms were created and the landscape of public programs became far more complete and complex. ${ }^{5}$

Despite this process, throughout this period, the FONDECYT's calls for proposals remained the most important horizontal mechanism for the funding of scientific research in Chile. Since its inception in 1982, FONDECYT supported 10,372 research projects (Figure 1) with average approval rates around $35 \%$ of all the submitted proposals.

\section{Figure 1 - Number of Research Projects Supported by FONDECYT per year}

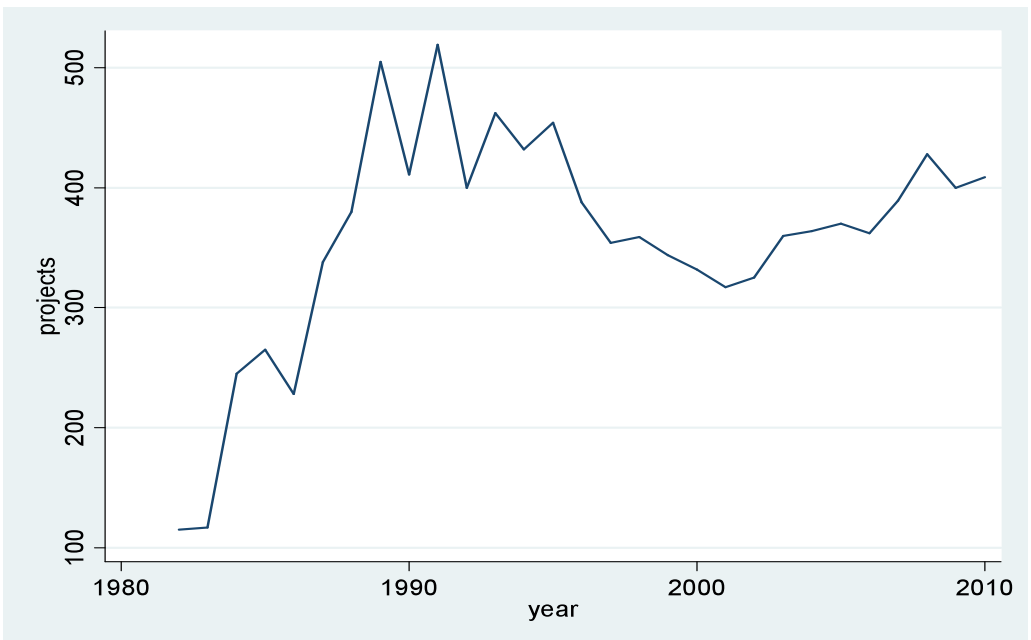

Source: CONICYT (2012): http://www.conicyt.cl/573/article-27736.html

To select the projects to be funded, FONDECYT operates on the basis of annual competitions, open to both individual researchers and research institutions. By design, FONDECYT is a totally neutral instrument and the quality of the research proposal is the only criterion to allocate funding. A National Council for Scientific and Technological Development - which includes the Ministers of Education, Planning, and Finance - is responsible for funds' allocation. The fund's operations are managed by

\footnotetext{
${ }^{3}$ Such as the Science and Technology Program (1990-1995), the Technology Innovation Program (19962000) and the Innovation and Technology Development Program (2001-2006).

${ }^{4}$ See National Council for Innovation and Competitiveness (2010), National Agenda for Innovation and Competitiveness (2010-2020).

${ }^{5}$ Particularly important was establishment of the National Technology Development Fund (FONTEC) managed by CORFO and of the National Fund for Scientific and Technological Development (FONDEF) managed by the CONICYT. The focus of FONTEC was on the funding of demand driven R\&D projects submitted by firms. On the other hand, FONDEF's focused on funding collaborative R\&D projects performed by public institutions and universities in collaboration with the private sector.
} 
two Superior Councils - one for science (seven members) and one for technological development (five members). In turn, these are supported by 23 study groups made up of subject specialists in the various fields of research. ${ }^{6}$ The two Superior Councils appear to function independently of any other formal linkage with CONICYT, except through the budget preparation process, and through "special initiatives".

The amount of funding per project systematically grew over time. Indeed while during the first five years of the program average funding was only about US\$10,000 per project, since mid-80s and during the 90s average support grew to about US\$ 50,000 per-project. During the last phase, and in particular, since the establishment of the new innovation strategy, average funding per-project grew to about US\$100,000. Despite the growing trends in the average funding, even under the best scenario of the end of the period, actual funding per project is less than one third of what is the norm in many developed countries. ${ }^{7}$ So, given its meager funding per project in comparison with international standards, it is a contentious issue whether the support provided by this program to Chilean researchers has been relevant enough as to have an impact in scientific productivity and, more importantly, on the quality of the research conducted in the country. ${ }^{8}$

\section{The Theoretical Framework9}

\subsection{The rationale behind public funding of science}

The two fundamental features of FONDECYT rationale are the public good nature of scientific research and the particular incentive system that governs the generation of high quality codified knowledge. Figure 2 synthetically represents the FONDECYT rationale. Since the seminal works by Nelson (1959) and Arrow (1962), scholars have frequently defined scientific knowledge as a durable public good, i.e. non-excludable, non-rival and cumulative. This public good nature of scientific knowledge provides the prime and basic justification for the public financing of research projects. In particular, the impossibility of completely appropriating the benefits arising from the generation of scientific knowledge causes a difference between the private and the social marginal return of science, making investment fall short of optimal levels. Furthermore, the nonrival and cumulative character of new knowledge intensifies the difficulty of creating incentives that can compensate for the non-appropriable profits. Finally, the uncertainty and indivisibility of knowledge investments cause an even greater sub-optimality in the allocation of resources.

\footnotetext{
${ }^{6}$ FONDECYT is administrated by a dedicated administrative unit, which includes 23 staff members and is led by an executive director, with the support of CONICYT staff (especially from the Information Department and Accounting Unit).

${ }^{7} \mathrm{We}$ are grateful to one of the anonymous referees for pointing out this key issue.

${ }^{8}$ However, the average support given by FONDECYT has in recent years significantly increased and it is now closer to the average support provided by other similar programs in Latin America, such as the Argentina's FONCYT (Codner, 2011).

${ }^{9}$ This section follows the survey on Economics of Science by the Office of Evaluation and Oversight of the IDB (IDB, 2006) and Chudnovsky et al. (2008).
} 
Figure 2 - The FONDECYT Rationale

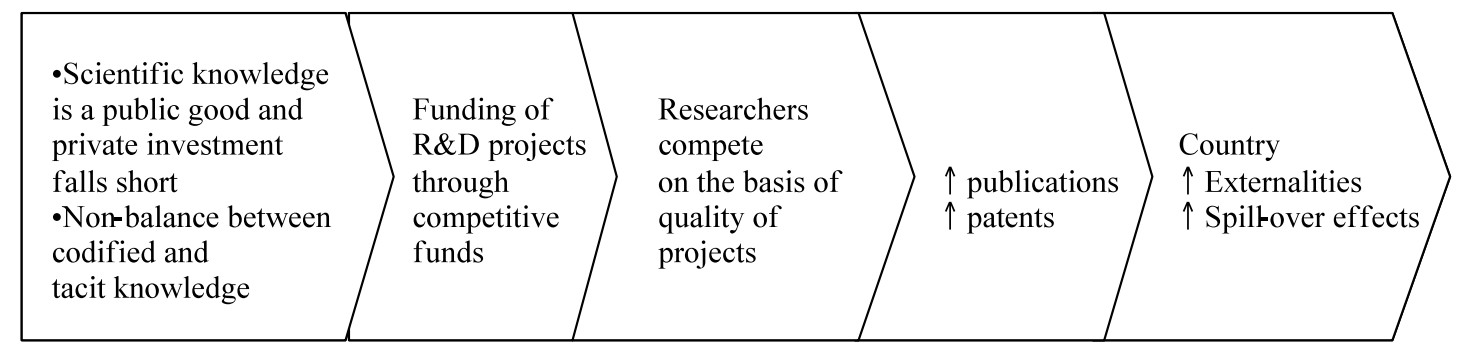

Source: Authors' elaboration

However, Dasgupta and David (1994) stress that the justification for the public support to scientific research goes beyond the need of correcting "market failures", arguing that the quality of being public (non tacit) is not inherent to knowledge. Indeed, researchers can make the decision to codify knowledge and make it available as information instead of maintaining it in tacit form. In this framework, public funding should also aim to provide the right incentives for maintaining a balanced allocation of research effort between scientific and technological research. Finally, the works of evolutionary scholars provide alternative justifications for the public funding of science and criticizes the public good argument by claiming that learning and transmission costs could significantly diminish both the non-rival and cumulative character of knowledge (Pavitt, 2001). The rationale for public support of scientific research has to be found in the dynamic and evolutive nature of the knowledge creation process. Public investment in science should foster systemic learning capabilities by training scientists (Salter and Martin, 2001), developing new methods (Rosenberg, 1992), creating knowledge networks (Lundvall, 1992) and increasing the capacity to solve problems (Patel and Pavitt, 2000).

The FONDECYT fund supports scientific research in Chile by providing grants through a competitive mechanism based on quality and experience. ${ }^{10}$ Nevertheless, some potential trade-offs are embedded in the specific parameters adopted in the selection process. Gambardella (2001) provides evidence of the effectiveness of funding scientists on the basis of their publication profile (excellence or experience criterion). This selection criterion not only leads to more and better publications, but it also reduces the probability of project failure. However, the adoption of the experience criterion may lead to the concentration of funding among a limited number of scientists or topics and less variety in the research portfolio. Indeed, Molas-Gallart and Salter (2002) criticize the excellence criterion arguing that research variety increases the probability of obtaining valuable research results. In this direction, criteria based on the quality of the research proposals usually assume more risks of project failure as a counterpart for research diversification. Additional allocation criteria, such as the portfolio system proposed by Scherer and Harhoff (2000) aim at pursuing a greater variety of research topics - diversification - and access to funding for new groups and younger researchers, thus increasing the program's outreach.

\footnotetext{
${ }^{10}$ The FONDECYT's strategy clearly falls into a subsidy category: the government grants subsidies to scientists to finance their research activities. Other strategies commonly identified by scholars and policy makers have been the French CNRS model (the government uses public resources to directly produce and diffuse scientific research through state-owned organizations where the scientists are public employees) and the granting of property rights (the government grants property rights to private researchers to foster the production of scientific knowledge).
} 
The FONDECYT program, as other scientific research funds, adopts a mix of criteria that try to balance the abovementioned tradeoffs. The FONDECYT evaluators rank the research proposals on the basis of four weighted criteria: (i) the quality of the research proposal (35\%); (ii) the project viability (25\%); (iii) the ability and productivity of the principal researcher $(29 \%)$ and, (iv) the ability and productivity of the secondary researchers (11\%). As can be seen from the weights distribution, the FONDECYT selection process gives some preference to the quality of the research proposal criterion. However, for well renowned researchers, especially those with previous but not necessarily current good publication performance, their CV may affect more than the project quality compared to a younger, unknown researcher. ${ }^{11}$ Another interesting feature of FONDECYT funding mechanism is that principal researchers are required to show evidence of submission of the project's outputs to an indexed journal as a condition for the formal completion of the project.

\subsection{Expected Outcomes and determinants of scientific productivity}

How should we evaluate the results of public support to science? The most generally accepted approach has been to use bibliometric data, since in general it is accepted that the number of publications can be a good measure of the production of codified knowledge and the possibility of access to this knowledge. ${ }^{12}$ Following Stephan (1996), a usual form to measure the importance of a scientist's contribution is through the number of publications with some weighting to correct for the quality of outputs. Although the typical way to control for quality has been to use the impact factor ${ }^{13}$ of the journals where those outputs were published, this measurement of quality depends on the field, the type and the size of the journal, fluctuates from year to year and it does not always provide an appropriate measure of the quality of scientist's publications (Amin and Mabe, 2000). For this reason, a direct measurement of citations to the articles produced by each scientist has been increasingly used to complement the number of publications.

Crespi and Geuna (2004) point out the importance of incorporating lags in the estimations of the results of scientific research, in order to catch the delay between the reception of the funds and actual publication. In an econometric study of a panel of OECD countries, they show that to identify the maximum impact of a given increase in the science budget on publications and citations it is necessary to wait between five to six years. ${ }^{14}$ Moreover, Crespi and Geuna (2005) emphasize that different fields are characterized by different propensities to publish in recognized journals, as well as by different time lags in reaching publication.

\footnotetext{
${ }^{11}$ In 2006, the FONDECYT established a new and separated competition for young researchers called "FONDECYT iniciación".

${ }^{12}$ Diamond (1986) provides empirical evidence for the relevance of this mechanism to determine salaries increases and promotions at universities. Debackere and Glänzel (2004) analyze the results of an experiment that consisted in distributing funds to Flemish universities on the basis of bibliometric output.

${ }^{13}$ Impact factors are no more than a measurement of the frequency with which the "average" article of a journal was mentioned in a certain year. In particular, the impact factor is calculated dividing the number of citations received by articles published during the two previous years in a given journal by the number of publications in those years in the same journal.

${ }^{14}$ In this direction, Arora and Gambardella (2005) consider the impact of public funding to economic researchers in the United States using the publications weighted by citations in a window of 5 years after the decision to grant the funding was taken.
} 
The literature on the economics of science has provided an increasing amount of empirical evidence regarding the variables that affect the number of publications by scientists (Stephan, 2010). Indeed, this literature suggests that scientists' publication productivity is non-linearly affected by age (Stephan, 1996) ${ }^{15}$, gender (Long, 2001), level of education of the researcher (Buchmueller et al., 1999), the availability of other sources of income (Stephan, 1996), the size and quality of the research laboratory (Turner and Mairesse, 2005) and the score obtained during the application process for research funding (Arora and Gambardella, 2005). In our empirical analysis we control for most of these influential covariates.

Finally, to fully understand the effects of national research funds such as FONDECYT on the different outputs one needs to consider how funding and the interaction between different sources of funding may affect researcher incentives and decisions. Funds for scientific research might come from many sources (contracts with other government entities, consultancy with private companies, support from multilateral organizations, aid from international donors, etc.) and these different sources of funds can be either complement or substitute. ${ }^{16}$ However, during our analysis period FONDECYT was practically the only national source of funding for scientific research in Chile. Although two other Chilean programs had potentially similar goals, their specific objectives and targets were quite different and, therefore, their potential overlap with FONDECYT almost nonexistent. In fact, the FONDEF program, also managed by CONICYT, targeted only university-industry technology transfer, while the President of the Republic Scholarship aimed at supporting post-graduate studies outside of Chile.

Some complementarity or substitution still might come from the funding for research provided by international cooperation. At that time Chile was emerging from a dictatorship and so international cooperation funds were available to support S\&T in Chile. Nevertheless, international cooperation funds usually focused on more applied research projects or problem solving activities and they were not aimed at generating publications in indexed journals. Therefore, in principle we expect that the overlap between FONDECYT and international cooperation funding to be rather weak as well. Moreover, although both the complementary or substitution effect of this international funding cannot be completely discarded, one should consider that this funding was available under the exact same conditions for both researchers that were supported by FONDECYT and those that were not.

\section{The Evaluation Strategy}

After reviewing the rationale of the FONDECYT program in light of the economics of science literature and having identified its potential outcomes, in this section we address the main research questions of this study: (i) what is the FONDECYT's impact on the

\footnotetext{
${ }^{15}$ See also Tuner and Mairesse (2005) and Gonzalez-Brambila and Veloso (2007).

${ }^{16}$ A type of "crowding in" (or "crowding out") phenomenon in relation to other available research funds may occur. On the one hand, science, technology and innovation activities are usually characterized by "supermodularity" or complementary (Mohnen and Roller, 2005). There might be situations in which a positive correlation between national research funds and other sources is expected, e.g. resources can be used to finance fixed capital costs or the riskier component of the research project. On the other hand, this relationship might also lead to a substitution effect. This would occur in situations in which the type of project being funded by research councils was very similar to the types of projects funded by other sources of funds. In this context, public funds might in fact be superfluous (Lach, 2002).
} 
number of publications produced by the financed scientists? (ii) What is the FONDECYT's impact on the quality of the publications produced by the financed scientists?

To answer these questions, we have to deal with the problem that the FONDECYT lacks of a monitoring system for collecting data and tracking outcomes of interest for both beneficiary and non-beneficiary researchers. We overcome this problem by using FONDECYT's administrative records combined with secondary data on the publication profile of scientists provided by the Science Citation Index from the Institute for Scientific Information (ISI-SCI) (Figure 3).

Figure 3 - FONDECYT Research Questions, Indicators and Data Sources

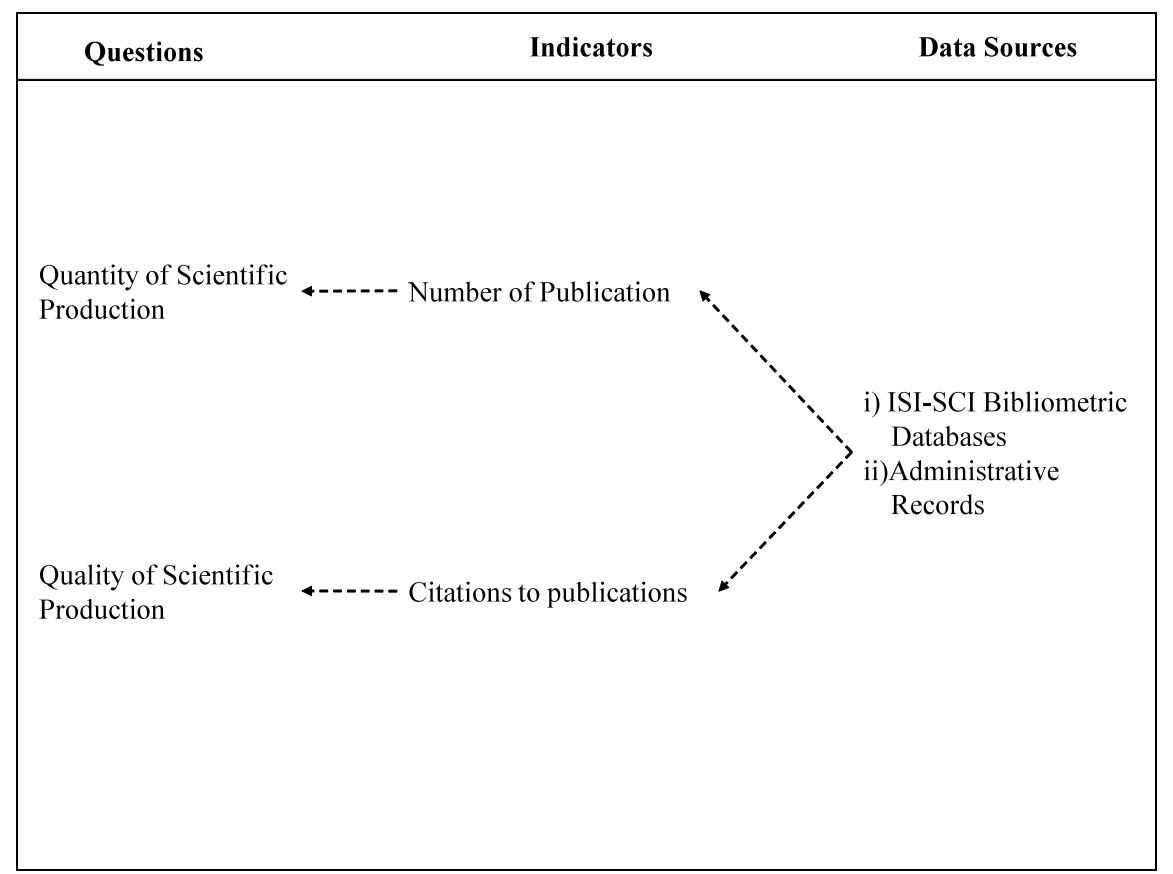

Source: Authors' elaboration

We then use this information to perform a quasi-experimental impact evaluation through a discontinuity regression design considering researchers who applied to the program between 1988 and 1997.

\subsection{Data Description}

To carry out this evaluation we set up a specific database in cooperation with the CONICYT's Information Unit. The data gathering process was organized into three phases: (i) identification of the population of reference; (ii) attribution of the scientists to the treatment and control groups; (iii) attribution of publications and citations to the selected scientists. 
i. Identification of the population: the population of reference includes (i) all Principal Researchers (PRs) whose projects received financial support of the program between 1988 and 1997 and, (ii) all PRs who applied to the program during that period, but were not financed because their projects ranked below the threshold for being admitted to funding.

ii. Definition of the treated and control groups: the treated group is formed by PRs that received FONDECYT's funding for the first time between 1988 and 1997 - i.e. they did not receive funding in the first six years of the program's life (1982-1987) - and did not receive funding from this program again at least in a six-year window from the year in which their first project was approved. The control group is formed by PRs that did not receive FONDECYT's funding between 1982 and 2002. For this control group, we consider the first competition in which PRs participated in our treatment period (1988-1997). ${ }^{17}$ Given that the program allows for the re-submission of projects, we do not include in the sample PRs whose projects were rejected in their first submission, but were accepted in later competitions. ${ }^{18}$

iii. Attribution of the bibliometric data: for PRs in both the treated and control groups we count the full set of publications included into the ISI-SCI and produced in the six-year window after the decision to grant the funding or deny it was taken. ${ }^{19}$ It is worth noting that the selection includes all publications up to December 2002. In this framework, younger publications may experience some censoring in their citations. Therefore, we consider all citations made up to December 2005 to minimize this potential problem.

Table 1 shows the main descriptive statistics of our working sample. Our sample includes 3,143 PRs, 886 PRs in the treatment group and 2,257 PRs in the control group. When analysing the main descriptive statistics of the two groups we get that, on average, treated PRs produced around 2 more publications than PRs in the control group. If we consider those researchers with a positive number of publications, ${ }^{20}$ publications of the control group received, on average, slightly more citations than the ones of the treated group. Projects in the treatment group had a much lower rank than projects in the control group (that is, they were closer to the top in terms of evaluation scores), however both groups are very similar on average in observed characteristics of the PR - age in the submission year and gender - and their projects - size in terms of the number of researchers in the research team, duration and presence of a foreign researcher in the team.

\footnotetext{
${ }^{17}$ We allow PRs to have rejected projects before 1988 for the control group and before its first approved project for the treated group.

${ }^{18}$ The inclusion of "switching projects" would have contaminated the treatment and control samples.

${ }^{19}$ By considering the full portfolio of publications we are able to estimate the potential spillover effects between those projects funded by FONDECYT and other research projects conducted by the same PR.

${ }^{20}$ There is a non-negligible reduction of the sample after considering only those researchers with at least one publication into the ISI-SCI (for a good discussion on the usage of ISI bibliometric data see Cameron, 2005). This might indicate that Chilean researchers are publishing in other language, such as Spanish. This is certainly a limitation of using ISI-SCI data, given its focus on scientific literature written in English (we are grateful to one of the referees who pointed out this important issue). However, because we are comparing Chilean PRs in both the treatment and control group, this and other problems -such as the "cronyism effect" (Narin, 1976) - that equally affect both groups should not be a threat to our evaluation strategy.
} 
Table 1 - Descriptive Statistics

\begin{tabular}{|c|c|c|c|c|c|c|c|c|c|}
\hline \multirow[t]{2}{*}{ VARIABLE } & & \multicolumn{3}{|c|}{ GRANT $=1$} & \multicolumn{3}{|c|}{ GRANT $=0$} & \multicolumn{2}{|c|}{ TOTAL } \\
\hline & & Mean & $\mathrm{SD}$ & Obs. & Mean & SD & Obs. & Mean & SD Obs. \\
\hline Publications & (Count) & 5.49 & 16.62 & 886 & 3.11 & 10.10 & 2,257 & 3.78 & $12.343,143$ \\
\hline Citations $^{21}$ & (Mean) & 6.88 & 11.35 & 465 & 7.42 & 25.77 & 803 & 7.22 & $21.621,268$ \\
\hline Ranking $^{22}$ & (Standardized) & -0.51 & 0.45 & 886 & 1.26 & 0.72 & 2,257 & 0.76 & $1.033,143$ \\
\hline Age & (Years) & 42.07 & 9.74 & 886 & 43.35 & 9.74 & 2,257 & 42.99 & $9.753,143$ \\
\hline Gender $^{23}$ & (Dummy) & 0.71 & 0.45 & 886 & 0.71 & 0.45 & 2,257 & 0.71 & $0.45 \quad 3,143$ \\
\hline Researchers & (Count) & 2.92 & 1.86 & 886 & 3.26 & 1.91 & 2,257 & 3.16 & $1.913,143$ \\
\hline Duration & (Years) & 2.10 & 0.69 & 886 & 2.05 & 0.71 & 2,257 & 2.06 & $0.713,143$ \\
\hline Foreign researcher ${ }^{24}$ & (Dummy) & 0.13 & 0.33 & 886 & 0.08 & 0.27 & 2,257 & 0.09 & $0.293,143$ \\
\hline
\end{tabular}

Source: Authors' elaboration

\subsection{The Econometric Strategy}

The impact of public financing of research funds such as the FONDECYT is a much less explored field than other policy evaluations. The identification of the impact of public financing has to deal with a quite clear potential selection bias: researchers whose projects are the best candidates for funding are also those researchers that would have the largest expected output in the absence of funding. In order to understand the evaluation problem, it is useful to specify the following knowledge production function:

$$
Y_{i, t+j}=\tau D_{i, t}+Z_{i, t} \mathrm{~B}+\alpha_{i}+\varepsilon_{i, t+j}
$$

where $Y_{i, t+j}$ is the research output (the number of publications in refereed journals by a PR $i$ during $j$ years after the decision to grant the funding or deny it was taken), $D_{i t}$ is a dummy variable that takes the value of 1 if researcher $i$ receives FONDECYT's grant at

\footnotetext{
${ }^{21}$ This outcome is the mean number of citations per publication included in the ISI-SCI, when the number of ISI publications is positive. That is, it excludes the cases of zero citations for zero publications.

${ }^{22}$ To facilitate the interpretation we have normalized the ranking of each year relative to the cut-off point. In other words, in each year the cut-off corresponds to the zero ranking.

23 "Gender" is a dummy variable that takes value one if the project leader gender is male and zero otherwise.

${ }^{24}$ "Foreign researcher" is a dummy variable that takes value one if the research team has at least one foreign member and zero otherwise.
} 
time $t, \tau$ is the impact for the researcher $i$ from receiving a grant, $Z_{i t}$ is a vector of observable determinants of research outputs and $\alpha_{i}$ represents non-observables (to the evaluator) from the researcher and therefore unobserved project quality. A primary obstacle to identification is the non-random assignment of treatments. In particular, selection for support on the basis of unobservables (by both applicants and CONICYT) may lead to a non-zero correlation between the treatment and those non-observables in the error term, $\operatorname{Cov}\left(\mathrm{D}_{i, t}, \alpha_{i}\right) \neq 0$. In this case, the treatment effect estimated using OLS might not reflect the program's causal effect on PRs' performance.

In order to overcome the selection problem, we adopted the so-called Regression Discontinuity (RD) design. This technique utilizes a discontinuity in the probability of selection that occurs at a particular threshold with respect to some index of quality to identify the treatment effect separately from the impact of quality. ${ }^{25}$ According to this design, assignment is solely based on whether a pre-intervention measure is above/below an established threshold. For instance, consider the case in which candidates are split into two groups according to whether the pre-intervention measure (for example, average evaluation by peers in the FONDECYT case) is above or below a specified threshold. Those who scored above the threshold received the grant while those who score below are denied it.

The regression discontinuity design approach relies on the maintained hypothesis that individuals with a score just below the threshold score are very similar in their observed and unobserved characteristics to individuals with score just above the threshold score. This design features both advantages and disadvantages. On the one hand, by exploiting the fact that within a neighbourhood around the cut-off subjects assigned to the control and treatment groups differ solely with respect to the variable on which the assignment to the intervention is established (and with respect to any other variable correlated to it), one can control for the confounding factors just by contrasting marginal participants to marginal non-participants. ${ }^{26}$ By doing this, the method allows for identifying the mean impact of intervention locally with respect to the cut-off point. Intuitively, for the identification to hold it must not be the case that a spurious discontinuity in the relationship between the outcome and the variable on which selection is based happens to coincide with the cut-off point. On the other hand, the design features two main limitations. Firstly, its applicability is by definition confined to those instances in which selection takes place based on an observable pre-intervention measure or on the basis of a deterministic process. Secondly, even when the design is feasible it only identifies the mean impact at the threshold for selection.

Considering equation (1) the implementation of the discontinuity regression approach is based on estimating the following regression:

$$
\begin{aligned}
& Y_{i, t+j}=\tau D_{i, t}+\left(x_{i, t}-c_{t}\right)+\gamma\left(x_{i, t}-c_{t}\right) D_{i, t}+Z_{i, t} B+u_{i, t+j} \\
& \forall=i, t\left(c_{t}-h \leq x_{i, t} \leq c_{t}+h\right)
\end{aligned}
$$

\footnotetext{
${ }^{25}$ The regression discontinuity design estimator was introduced by Thistlethwaite and Campbell (1960). In the economic literature this estimator has been recently used by Black (1999), Angrist and Lavy (1999), DiNardo and Lee (2004), Van Der Klaauw (2002), Lalive (2008) and Urquiola and Vergoogen (2009). The identification and estimation of treatment effects are discussed in Hahn et al. (2001), Imbens and Lemieux (2008), Lee and Lemieux (2009) and Imbens and Wooldridge (2009).

${ }^{26}$ In this context, the term marginal refers to those researchers whose projects are not too far from the threshold or cut-off point for selection.
} 
where the new variable $x_{i, t}$ is the ranking given to the research project during the assessment and $c$ is the cut-off ranking (that changes for different years). The treatment estimator is given by $\tau$ while the interaction term controls by the possibility that the slopes of the outcome function at both sides of the cut-off be different. Finally $h$ is the "bandwidth" that determines how far each observation should be from the cut-off point in order to be included in the estimation sample. This version of the discontinuity regression approach is called in the evaluation literature as "Sharp Regression Discontinuity" (SRD) design.

In order to provide unbiased results of treatment impacts a SRD design requires that the forcing variable or ranking captures all the information regarding the quality of both the projects and their researchers and that funding decision be based only on this rank. The situation becomes more complicated when the granting agency, based on additional information not captured on the rank assessment, makes a decision "to pass" some projects that otherwise would have been rejected - projects just above the cut-off rank and to reject some marginal projects that otherwise would have been passed - projects just below the cut-off rank. In this case some sort of sample selection bias "at the margin" could still remain. This context is known as a "Fuzzy Regression Discontinuity" (FRD) design. In this case we need to estimate (2) by using instrumental variables. ${ }^{27}$ Following Jaffe (2002) a good instrument under this situation is a dummy variable that takes a value of 1 whenever the ranking is below the cut-off. In other words the instrument would be:

$$
1\left\{x_{i, t} \leq c_{t}\right\}
$$

This instrument should be highly correlated with the treatment dummy $\left(D_{i, t}\right)$ by construction, but because we are already controlling for the ranking in the regression $\left(x_{i, t}\right)$, it should not be correlated with the error term. Both $S R D$ and $F R D$ approaches will be applied in this paper.

\section{Empirical Results}

\subsection{Graphing discontinuities and testing the RD design}

In the first stage of our analysis we study the relationship between the ranking obtained by projects and the number of ISI publications (citations) generated by the PRs. For this purpose, we estimate this relationship through a local linear regression just to the left and right of the cut-off point, ${ }^{28}$ using as dependent variable the frequency of publications (mean citations per publication) and as independent variable the ranking

\footnotetext{
${ }^{27}$ The treatment effect can be recovered by computing the ratio of the jump in the outcome variable at the threshold (discontinuity jump in the relation between $Y_{i}$ and $x_{i}$ ) to the jump in the probability of participation in FONDECYT also at the threshold (discontinuity jump between $D_{i}$ and $x_{i}$ ).

${ }^{28}$ We let the regression function differ on both sides of the cut-off point (see Imbens and Lemieux, 2008; Lee and Lemieux, 2009; and Imbens and Wooldridge, 2009). For all local linear regressions we use a triangle (edge) Kernel.
} 
obtained by the projects. ${ }^{29}$ We consider several bandwidths including the "optimal bandwidth" proposed by Imbens and Kalyanaraman (2009). ${ }^{30}$ For the regression discontinuity approach to be valid we should observe some sort of discontinuity of the output function at or near the cut-off point.

Results can be seen in the two top panels of Figure 4. The top left panel shows the local linear regression results for publications. In this case, the "jump" at the cut-off point indicates that the discontinuous change in eligibility increases the number of publications of the researchers. Supported PRs whose projects are at the top of the ranking produced more publications.

\section{Figure 4 -The Relationship between Project's Ranking and Research Outputs of FONDECYT's principal researchers}
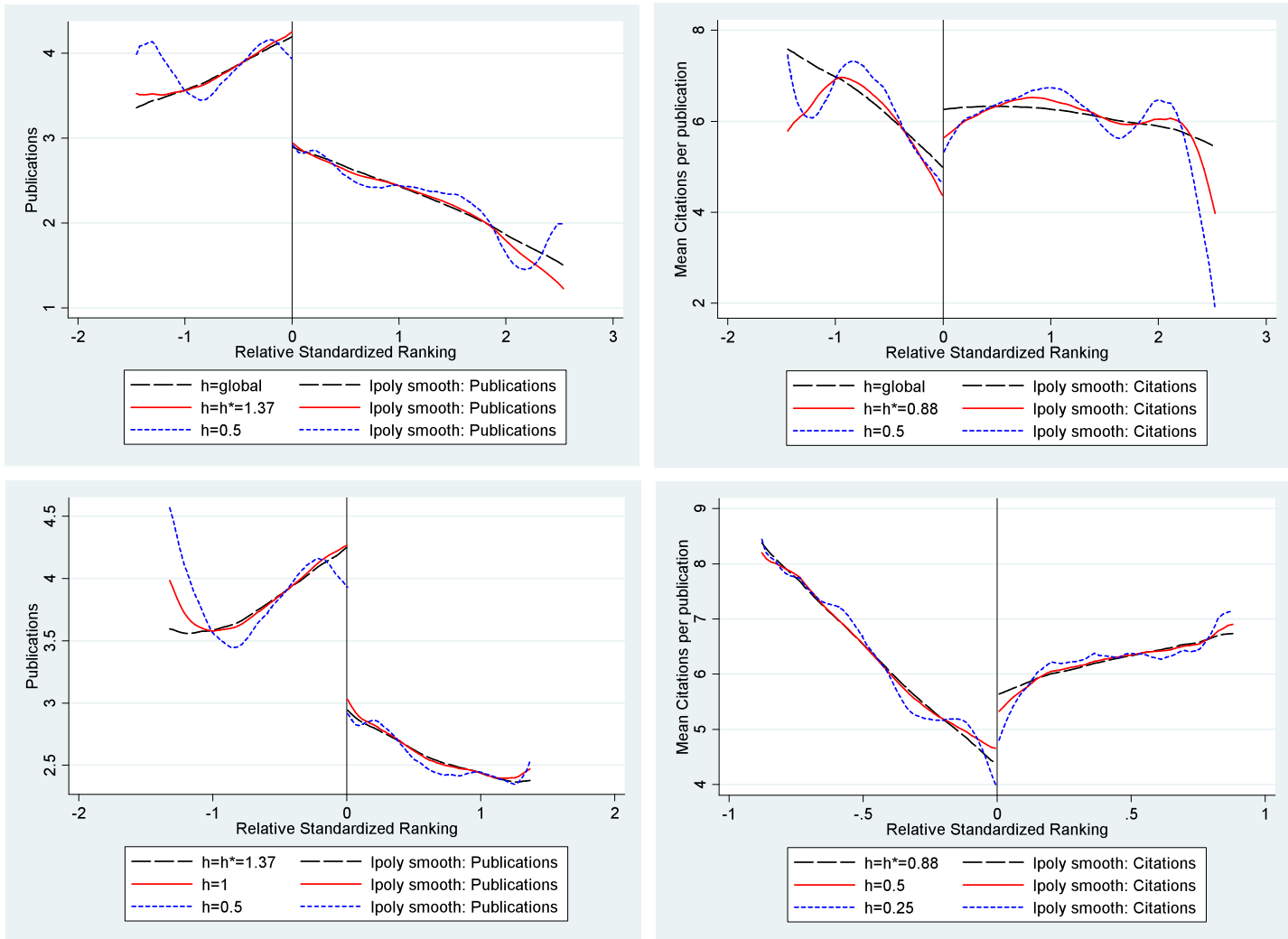

Source: Authors' elaboration

The top right panel in Figure 4 shows the local linear regression results for citations. The graph suggests that PRs with projects with the highest score not necessarily produced higher quality publications (publications that were cited more often). Quite surprisingly, we find that around the cut-off point, where the discontinuity is smaller, those researchers whose projects were ranked above the cut-off point had higher quality publications than those below it. An interesting conclusion of combining these two

\footnotetext{
${ }^{29}$ For all estimations on publications and citations the outliers were dropped for each outcome separately using the following rule-of-thumb: $Y_{i}$ is an outlier if $Y_{i}>\mathrm{E}\left(Y_{i}\right)+3 \cdot \operatorname{SD}\left(Y_{i}\right)$. Appendix I displays the distribution of publications and citations after this procedure.

${ }^{30}$ We estimate the "Optimal bandwidth" for each outcome separately following the routine for Stata ("rdob”) developed by Fuji, Imbens and Kalyanaraman (2009).
} 
graphs is that FONDECYT's reviewers could have tended to give more weight to researchers that were expected to produce more publications regardless of their quality.

One potential problem with the two graphs in the top panels of Figure 4 is that the local linear regression is estimated across the full support of the forcing variable. According to Imbens and Lemieux (2008) this could harm visual clarity of any discontinuity in the outcome functions. To improve our analysis, we compute local linear regressions considering only those researchers with a project's ranking within the "optimal bandwidth" around the cut-off point. Both bottom graphs of Figure 4 reinforce our previous conclusions. The bottom left panel suggests that there is an important discontinuity for publications. However, the bottom right panel indicates that impact could even be negative for citations.

Before proceeding with the estimations, we need to determine what sort of discontinuity regression design should be used for the analysis. One way of doing this is by plotting the treatment variable by project's ranking to see if there is a sudden drop in the treatment probability at the cut-off point.

Figure 5 shows the results of this analysis. The figure plots the treatment probability by project's ranking using local linear regression with several bandwidths. The graph suggests that not all the researchers with projects with ranks below the cut-off point were selected for financing and that not all researchers with projects with ranks above the cut-off point were rejected. In other words, the results indicate that there is significant mobility "at the margin" and that a FRD approach might be more adequate for the estimations.

\section{FIGURE 5 - FONDECYT TREATMENT PROBABILITY AND PROJECT'S RANKING}

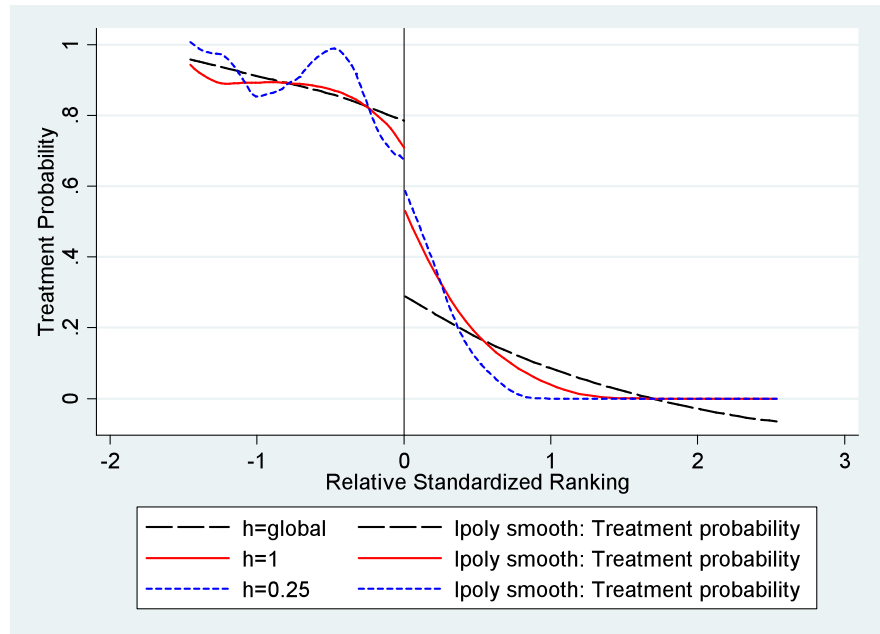

Source: Authors' elaboration

We then implement two tests to validate the use of the RD design. First, although the underlying assumption that each researcher has imprecise control over the forcing 
variable cannot be test directly, ${ }^{31}$ we can test whether there is a discontinuity in the density of the forcing variable, following McCrary (2008). For this purpose, we inspect the histogram of the forcing variable and the kernel density estimates over bins with a bandwidth of 0.05 ( 80 bins in the graph - Figure 6, top left panel) and then we use the frequencies within the bins generated as a dependent variable in a local linear regression on both sides of the cut-off point (Figure 6, top right panel). We also compute a similar procedure with standard error bands in the bottom panel of Figure $6 .^{32} \mathrm{We}$ find no sign of a jump in density of observations at or near the cut-off point, and therefore conclude that the data show no evidence of manipulation of the assignment variable.

\section{FIGURE 6 - Density and Frequency of projects by Ranking}
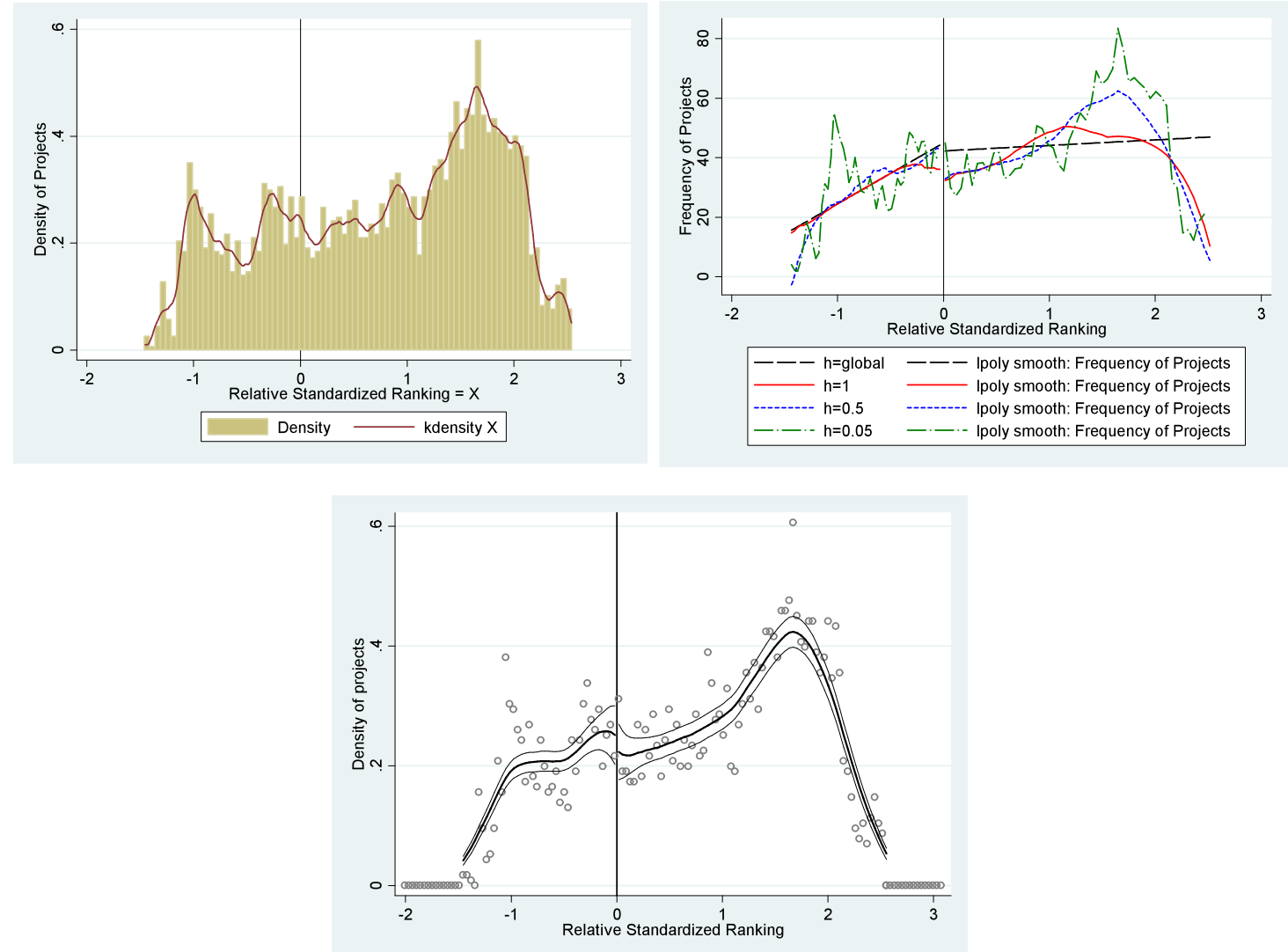

Source: Authors' elaboration

We also test the validity of the RD design by inspecting whether our main observed characteristics of PRs and projects are "locally" balanced on either side of the cut-off point. Figure 7 displays the local linear regression estimation for each of those characteristics (specifically from the left to right: age and gender of the PR, number of researchers in team, duration of the project and presence of a foreign researcher in the

\footnotetext{
${ }^{31}$ This assumption supports the idea of local random assignment of the treatment around the cut-off point. See Lee and Lemieux (2009).

32 We estimate the bottom panel of Figure 6 by using the routine "DCdensity" proposed by McCrary and Novak in http://emlab.berkeley.edu/ jmccrary/DCdensity/.
} 
team). Although the graphs show in general no evidence of discontinuity at or near the cut-off, some small discontinuities appear in particular when we use the smallest bandwidths. ${ }^{33}$ To avoid any possible bias, we include all these covariates as control variables in our estimation.

Figure 7. Main observed characteristics by project's ranking
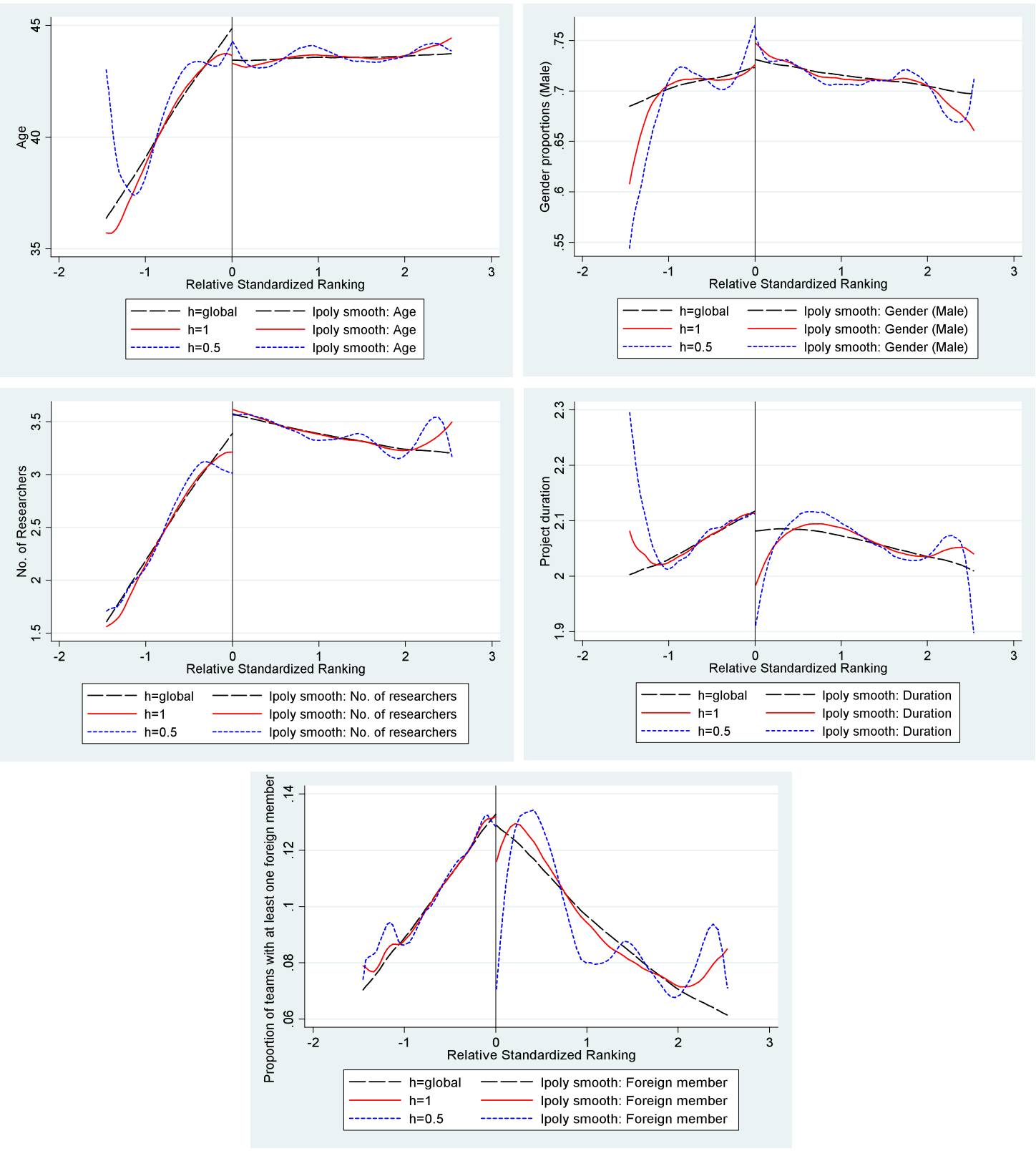

Source: Authors' elaboration

\footnotetext{
${ }^{33}$ However, it is worth mentioning that while discontinuities in the outcomes are robust to different bandwidths and types of Kernels, in the graphs of Figure 7 the small discontinuities are very dependent on bandwidth selection and tend to disappear when using a different Kernel.
} 


\subsection{Estimation Results}

In what follows we present the results for the impacts on publications and citations using parametric (OLS and IV) and non-parametric techniques. ${ }^{34}$ For both outcomes we consider several bandwidths. ${ }^{35}$ Table 2 summarises the results of the SRD when the dependent variable is the number of publications and the estimation technique is OLS. We find that in the sample around the cut-off point FONDECYT has a positive and significant impact of around 2 publications.

Table 2 - Treatment Effects on Number of Publications, OLS estimates

\begin{tabular}{|c|c|c|c|c|c|c|}
\hline & (1) & (2) & (3) & (4) & $(5)$ & (6) \\
\hline COEFFICIENT & All & $\mathrm{h}=1.87$ & $h=1.62$ & $\mathrm{~h}^{*}=1.37$ & $\mathrm{~h}=1.12$ & $\mathrm{~h}=0.87$ \\
\hline $\mathrm{D}$ & $\begin{array}{c}1.5709 * * * \\
(0.439)\end{array}$ & $\begin{array}{c}1.7464 * * * \\
(0.453)\end{array}$ & $\begin{array}{c}1.7485^{* * *} \\
(0.459)\end{array}$ & $\begin{array}{c}1.8714 * * * \\
(0.474)\end{array}$ & $\begin{array}{c}1.7767 * * * \\
(0.493)\end{array}$ & $\begin{array}{c}1.3067 * * \\
(0.584)\end{array}$ \\
\hline$X$ & $\begin{array}{c}-0.1379 \\
(0.156)\end{array}$ & $\begin{array}{c}0.1003 \\
(0.205)\end{array}$ & $\begin{array}{c}0.0289 \\
(0.243)\end{array}$ & $\begin{array}{c}0.1450 \\
(0.305)\end{array}$ & $\begin{array}{l}0.1279 \\
(0.373)\end{array}$ & $\begin{array}{c}-0.9314 \\
(0.648)\end{array}$ \\
\hline D_X & $\begin{array}{l}1.0422^{*} \\
(0.543)\end{array}$ & $\begin{array}{l}0.9228 \\
(0.571)\end{array}$ & $\begin{array}{c}0.9997^{*} \\
(0.592)\end{array}$ & $\begin{array}{l}1.0115 \\
(0.617)\end{array}$ & $\begin{array}{l}0.9635 \\
(0.711)\end{array}$ & $\begin{array}{l}1.9960 * \\
(1.035)\end{array}$ \\
\hline Age & $\begin{array}{c}-0.0178^{*} \\
(0.010)\end{array}$ & $\begin{array}{l}-0.0155 \\
(0.012)\end{array}$ & $\begin{array}{l}-0.0191 \\
(0.013)\end{array}$ & $\begin{array}{c}-0.0243^{*} \\
(0.015)\end{array}$ & $\begin{array}{l}-0.0279 \\
(0.017)\end{array}$ & $\begin{array}{l}-0.0215 \\
(0.020)\end{array}$ \\
\hline Gender & $\begin{array}{l}0.1314 \\
(0.232)\end{array}$ & $\begin{array}{l}-0.0632 \\
(0.263)\end{array}$ & $\begin{array}{l}-0.1267 \\
(0.282)\end{array}$ & $\begin{array}{c}-0.0732 \\
(0.318)\end{array}$ & $\begin{array}{l}-0.1660 \\
(0.363)\end{array}$ & $\begin{array}{l}-0.2883 \\
(0.424)\end{array}$ \\
\hline No. of researchers & $\begin{array}{c}0.1029 * \\
(0.060)\end{array}$ & $\begin{array}{l}0.0853 \\
(0.069)\end{array}$ & $\begin{array}{l}0.1130 \\
(0.077)\end{array}$ & $\begin{array}{l}0.0971 \\
(0.087)\end{array}$ & $\begin{array}{l}0.1052 \\
(0.094)\end{array}$ & $\begin{array}{l}0.0423 \\
(0.107)\end{array}$ \\
\hline Duration & $\begin{array}{c}0.2394^{*} \\
(0.145)\end{array}$ & $\begin{array}{l}0.1875 \\
(0.165)\end{array}$ & $\begin{array}{l}0.1645 \\
(0.182)\end{array}$ & $\begin{array}{l}0.2657 \\
(0.195)\end{array}$ & $\begin{array}{l}0.3023 \\
(0.216)\end{array}$ & $\begin{array}{c}0.4506^{*} \\
(0.266)\end{array}$ \\
\hline Foreign member & $\begin{array}{l}-0.4198 \\
(0.360)\end{array}$ & $\begin{array}{c}-0.3674 \\
(0.391)\end{array}$ & $\begin{array}{c}-0.2546 \\
(0.436)\end{array}$ & $\begin{array}{l}-0.4275 \\
(0.462)\end{array}$ & $\begin{array}{l}-0.0804 \\
(0.524)\end{array}$ & $\begin{array}{l}-0.0554 \\
(0.584)\end{array}$ \\
\hline Constant & $\begin{array}{c}1.6854^{* *} \\
(0.789)\end{array}$ & $\begin{array}{l}1.6342 * \\
(0.940)\end{array}$ & $\begin{array}{l}1.8775^{*} \\
(1.051)\end{array}$ & $\begin{array}{c}2.1329 * \\
(1.202)\end{array}$ & $\begin{array}{l}2.0928 \\
(1.335)\end{array}$ & $\begin{array}{c}2.7497 * \\
(1.617)\end{array}$ \\
\hline Observations & 3,101 & 2,634 & 2,272 & 1,942 & 1,632 & 1,208 \\
\hline R-squared & 0.056 & 0.054 & 0.060 & 0.063 & 0.064 & 0.073 \\
\hline
\end{tabular}

Robust standard errors in parentheses, ${ }^{* * *} \mathrm{p}<0.01,{ }^{* *} \mathrm{p}<0.05,{ }^{*} \mathrm{p}<0.10$

Scientific Disciplines, Region and Year dummies included. " $D$ " is the treatment variable, " $X$ " is the forcing variable (relative standardized ranking) and " $D_{-} X$ " is the interaction term.

\footnotetext{
${ }^{34}$ For the non-parametric approach we estimate local linear regressions on both sides of the cut-off using a triangle Kernel in a FRD framework. We compute the ratio of the jump in outcome to the jump in treatment (Local Wald estimate).

${ }^{35}$ We first consider the full sample. We then use the Imbens-Kalyanaraman "optimal bandwidth" that determines how far each observation should be from the cut-off point in order to be included in the estimation sample. Finally, to see how robust these results are we estimate the impact on both outcomes by using four additional bandwidths that arise from increasing and reducing the "optimal bandwidth" in 0.25 and 0.50 points.

${ }^{36}$ The scientific disciplines are divided into: Agronomy/Zoology, Social Sciences, Natural Sciences, Earth Sciences, Engineering Sciences, Medical Sciences, Legal-Economic-Management Sciences and Humanities (see Appendix II). The regions included are: Region of Tarapaca, Antofagasta, Atacama, Coquimbo, Valparaiso, Libertador G.B. O’Higgins, Maule, Bio-Bio, Araucania, Los Rios, Los Lagos, Magallanes and the Antartica Chilena, Arica and Parinacota, Metropolitan Zone and particular researchers. Finally, we consider year dummies from 1988 to 1997 (see Appendix III).
} 
Table 3 shows the results when we adopt a FRD design and estimate the program's impact on publications using instrumental variables. We use the dummy variable defined by Equation 3 as instrument for the treatment dummy and its interaction with the ranking as instrument for the interaction between the treatment dummy and the ranking. The results in Table 3 show that the impact is statically significant and numerically larger (up to 6 publications) than the impact estimated with OLS. Overall, the results estimated with a FRD design confirm that the program still has a significant impact on publications even when one controls for selection at the margin.

Table 3 - Treatment Effects on Number of Publications, IV estimates

\begin{tabular}{|c|c|c|c|c|c|c|}
\hline & (1) & (2) & (3) & (4) & (5) & (6) \\
\hline COEFFICIENT & All & $\mathrm{h}=1.87$ & $h=1.62$ & $\mathrm{~h}^{*}=1.37$ & $\mathrm{~h}=1.12$ & $\mathrm{~h}=0.87$ \\
\hline $\mathrm{D}$ & $\begin{array}{c}2.9938 * * * \\
(1.065)\end{array}$ & $\begin{array}{c}3.5689 * * * \\
(1.192)\end{array}$ & $\begin{array}{c}3.7512 * * * \\
(1.325)\end{array}$ & $\begin{array}{c}4.2902 * * * \\
(1.583)\end{array}$ & $\begin{array}{c}4.9642 * * \\
(1.985)\end{array}$ & $\begin{array}{c}6.3432^{*} \\
(3.474)\end{array}$ \\
\hline $\mathrm{X}$ & $\begin{array}{l}0.1886 \\
(0.299)\end{array}$ & $\begin{array}{l}0.6557 \\
(0.424)\end{array}$ & $\begin{array}{l}0.7520 \\
(0.567)\end{array}$ & $\begin{array}{l}1.2963 \\
(0.854)\end{array}$ & $\begin{array}{l}2.1680 \\
(1.364)\end{array}$ & $\begin{array}{l}3.2483 \\
(2.867)\end{array}$ \\
\hline D_X & $\begin{array}{c}1.9100^{* * * *} \\
(0.727)\end{array}$ & $\begin{array}{c}1.6728^{* *} \\
(0.739)\end{array}$ & $\begin{array}{c}1.6704^{* *} \\
(0.744)\end{array}$ & $\begin{array}{l}1.3610^{*} \\
(0.786)\end{array}$ & $\begin{array}{l}0.6928 \\
(1.025)\end{array}$ & $\begin{array}{c}1.0658 \\
(1.501)\end{array}$ \\
\hline Age & $\begin{array}{c}-0.0203^{* *} \\
(0.010)\end{array}$ & $\begin{array}{c}-0.0190 \\
(0.012)\end{array}$ & $\begin{array}{c}-0.0235^{*} \\
(0.013)\end{array}$ & $\begin{array}{c}-0.0316^{* *} \\
(0.015)\end{array}$ & $\begin{array}{c}-0.0423^{* *} \\
(0.019)\end{array}$ & $\begin{array}{c}-0.0439 * \\
(0.026)\end{array}$ \\
\hline Gender & $\begin{array}{l}0.1405 \\
(0.232)\end{array}$ & $\begin{array}{l}-0.0521 \\
(0.263)\end{array}$ & $\begin{array}{l}-0.1038 \\
(0.283)\end{array}$ & $\begin{array}{l}-0.0478 \\
(0.319)\end{array}$ & $\begin{array}{l}-0.1277 \\
(0.366)\end{array}$ & $\begin{array}{r}-0.2812 \\
(0.438)\end{array}$ \\
\hline No. of researchers & $\begin{array}{l}0.0872 \\
(0.061)\end{array}$ & $\begin{array}{l}0.0637 \\
(0.071)\end{array}$ & $\begin{array}{l}0.0837 \\
(0.080)\end{array}$ & $\begin{array}{l}0.0610 \\
(0.091)\end{array}$ & $\begin{array}{l}0.0535 \\
(0.101)\end{array}$ & $\begin{array}{r}-0.0217 \\
(0.124)\end{array}$ \\
\hline Duration & $\begin{array}{l}0.2307 \\
(0.145)\end{array}$ & $\begin{array}{l}0.1757 \\
(0.166)\end{array}$ & $\begin{array}{c}0.1468 \\
(0.183)\end{array}$ & $\begin{array}{l}0.2298 \\
(0.197)\end{array}$ & $\begin{array}{l}0.2398 \\
(0.223)\end{array}$ & $\begin{array}{l}0.3177 \\
(0.296)\end{array}$ \\
\hline Foreign member & $\begin{array}{r}-0.4830 \\
(0.365)\end{array}$ & $\begin{array}{l}-0.4484 \\
(0.398)\end{array}$ & $\begin{array}{r}-0.3549 \\
(0.444)\end{array}$ & $\begin{array}{l}-0.5374 \\
(0.474)\end{array}$ & $\begin{array}{l}-0.2228 \\
(0.539)\end{array}$ & $\begin{array}{l}-0.4471 \\
(0.668)\end{array}$ \\
\hline Constant & $\begin{array}{l}0.9575 \\
(0.988)\end{array}$ & $\begin{array}{l}0.5511 \\
(1.192)\end{array}$ & $\begin{array}{l}0.6755 \\
(1.340)\end{array}$ & $\begin{array}{l}0.6537 \\
(1.559)\end{array}$ & $\begin{array}{l}0.3048 \\
(1.750)\end{array}$ & $\begin{array}{l}0.0295 \\
(2.490)\end{array}$ \\
\hline Observations & 3,101 & 2,634 & 2,272 & 1,942 & 1,632 & 1,208 \\
\hline R-squared & 0.052 & 0.047 & 0.051 & 0.049 & 0.036 & 0.007 \\
\hline
\end{tabular}

Robust standard errors in parentheses, ${ }^{* *} \mathrm{p}<0.01,{ }^{* *} \mathrm{p}<0.05,{ }^{*} \mathrm{p}<0.10$

Scientific Disciplines, Region and Year dummies included. " $D$ " is the treatment variable, " $X$ " is the forcing variable (relative standardized ranking) and " $D_{-} X$ " is the interaction term.

Source: Authors' elaboration

Adopting the same approach, we estimate the impact of FONDECYT on the mean number of citations per publication. In this case, we find no significant impact, consistently with the outcome plots of Figure 4. Table 4 and 5 summarize the results for the citation outcome variable and show that when using both OLS (Table 4) and IV 
(Table 5) techniques, the treatment variable is negative in almost all cases, though never statistically significant. ${ }^{37}$

Table 4 - Treatment Effects on Mean Number of Citations per publication, OLS estimates

\begin{tabular}{lcccccc}
\hline & $(1)$ & $(2)$ & $(3)$ & $(4)$ & $(5)$ & $(6)$ \\
\hline COEFFICIENT & All & $\mathrm{h}=1.38$ & $\mathrm{~h}=1.13$ & $\mathrm{~h}^{*}=0.88$ & $\mathrm{~h}=0.63$ & $\mathrm{~h}=0.38$ \\
$\mathrm{D}$ & & & & & & \\
& -0.5738 & -0.5629 & -0.7688 & -0.7650 & -0.2398 & -0.7209 \\
$\mathrm{X}$ & $(0.663)$ & $(0.704)$ & $(0.732)$ & $(0.780)$ & $(0.894)$ & $(1.095)$ \\
& -0.6040 & -1.2005 & -1.5890 & -2.0052 & -2.5329 & -3.5919 \\
D_X & $(0.707)$ & $(0.949)$ & $(1.136)$ & $(1.711)$ & $(2.144)$ & $(4.206)$ \\
& -0.1738 & 0.2871 & 0.3037 & 0.3597 & 2.0913 & 3.9062 \\
Age & $(0.381)$ & $(0.622)$ & $(0.697)$ & $(1.080)$ & $(1.826)$ & $(3.908)$ \\
& -0.0414 & -0.0260 & -0.0353 & -0.0494 & -0.0420 & -0.0520 \\
Gender & $(0.028)$ & $(0.030)$ & $(0.035)$ & $(0.040)$ & $(0.045)$ & $(0.053)$ \\
& -0.2074 & -0.4311 & -0.5511 & -0.6856 & 0.0289 & 0.5075 \\
No. of researchers & $(0.504)$ & $(0.584)$ & $(0.636)$ & $(0.777)$ & $(0.772)$ & $(0.848)$ \\
& -0.0353 & 0.2087 & 0.0627 & 0.0006 & 0.0859 & 0.3596 \\
Duration & $(0.117)$ & $(0.163)$ & $(0.148)$ & $(0.164)$ & $(0.202)$ & $(0.262)$ \\
& 0.2670 & -0.2802 & -0.2915 & -0.0364 & -0.5287 & -0.8526 \\
Foreign member & $(0.362)$ & $(0.380)$ & $(0.415)$ & $(0.455)$ & $(0.574)$ & $(0.739)$ \\
& 0.9518 & 1.0715 & 1.3015 & 0.7581 & 0.7858 & 0.8577 \\
& $(0.778)$ & $(0.990)$ & $(1.031)$ & $(1.021)$ & $(1.107)$ & $(1.444)$ \\
Constant & & & & & & \\
& $4.9463 *$ & $4.4102 *$ & $5.7221 * *$ & 4.1168 & 3.9966 & 4.8012 \\
Observations & $(2.567)$ & $(2.419)$ & $(2.695)$ & $(2.528)$ & $(2.816)$ & $(3.543)$ \\
R-squared & 1,261 & 896 & 777 & 576 & 418 & 280 \\
Robust & 0.057 & 0.050 & 0.064 & 0.080 & 0.100 & 0.145 \\
\hline
\end{tabular}

Robust standard errors in parentheses, ${ }^{* *} \mathrm{p}<0.01,{ }^{* *} \mathrm{p}<0.05,{ }^{*} \mathrm{p}<0.10$

Scientific Disciplines, Region and Year dummies included. " $D$ " is the treatment variable, " $X$ " is the forcing variable (relative standardized ranking) and " $D \_X$ " is the interaction term.

Source: Authors' elaboration

Our findings are confirmed and reinforced when we re-estimate both the impact on number of publications and mean number of citations per publication using a nonparametric approach (Table 6). ${ }^{38}$ Indeed, we still find a positive and significant impact of FONDECYT on number of publications while a mainly negative and non-significant impact on mean number of citations. ${ }^{39}$

\footnotetext{
${ }^{37}$ Given the distribution of publications and citations - right skewed with clumping at zero and a variance nearly 3 times greater than the mean, Appendix I - we replicate estimates in Tables 2 to 4 by using a Negative Binomial Model - this model accounts better for overdispersion than the Poisson regression model, which assumes that the mean and variance are the same. The results are similar to those presented in the paper in terms of the magnitude, sign and significance of the impact of the program. For the sake of brevity we present them in a summary table in Appendix IV.

${ }^{38}$ Non-parametric results are robust to different types of Kernels.

${ }^{39}$ In Appendix V we evaluate the dependence of the non-parametric estimates on bandwidth selection. Both graphs show the usual trade-off between bias and variance. However, the estimated effect for citations is clearly more sensitive to bandwidth selection.
} 
Table 5 - Treatment Effects on Mean Number of Citations per publication, IV estimates

\begin{tabular}{lcccccc}
\hline & $(1)$ & $(2)$ & $(3)$ & $(4)$ & $(5)$ & $(6)$ \\
\hline COEFFICIENT & All & $\mathrm{h}=1.38$ & $\mathrm{~h}=1.13$ & $\mathrm{~h}^{*}=0.88$ & $\mathrm{~h}=0.63$ & $\mathrm{~h}=0.38$ \\
$\mathrm{D}$ & -1.1455 & -0.8072 & -2.6081 & -14.3506 & 7.4605 & -2.6692 \\
& $(2.086)$ & $(3.570)$ & $(4.833)$ & $(17.196)$ & $(14.594)$ & $(6.569)$ \\
$\mathrm{X}$ & -0.2528 & -0.8405 & -0.3826 & 3.3230 & -8.8006 & -4.8268 \\
& $(0.989)$ & $(1.710)$ & $(2.471)$ & $(7.219)$ & $(6.484)$ & $(8.993)$ \\
D_X & -0.4755 & 0.0172 & -1.2949 & -11.6855 & 12.4258 & 2.9194 \\
& $(0.798)$ & $(2.318)$ & $(3.659)$ & $(15.331)$ & $(15.791)$ & $(10.663)$ \\
Age & -0.0407 & -0.0252 & -0.0248 & 0.0537 & -0.0897 & -0.0363 \\
& $(0.029)$ & $(0.036)$ & $(0.048)$ & $(0.141)$ & $(0.092)$ & $(0.070)$ \\
Gender & -0.2062 & -0.4297 & -0.5448 & -0.3099 & 0.0011 & 0.4585 \\
& $(0.504)$ & $(0.584)$ & $(0.644)$ & $(1.013)$ & $(0.835)$ & $(0.893)$ \\
No. of researchers & -0.0361 & 0.2083 & 0.0863 & 0.1369 & 0.0008 & 0.3880 \\
& $(0.120)$ & $(0.169)$ & $(0.169)$ & $(0.253)$ & $(0.286)$ & $(0.270)$ \\
Duration & 0.2635 & -0.2827 & -0.2858 & 0.1759 & -0.7077 & -0.6950 \\
& $(0.362)$ & $(0.381)$ & $(0.416)$ & $(0.602)$ & $(0.677)$ & $(0.878)$ \\
Foreign member & 0.9586 & 1.0690 & 1.3945 & 1.7953 & 0.1339 & 1.0719 \\
& $(0.771)$ & $(0.984)$ & $(1.034)$ & $(1.603)$ & $(1.829)$ & $(1.767)$ \\
Constant & & & & & & \\
& $5.4987 *$ & 4.6178 & $6.8602 *$ & 10.5930 & 0.2906 & 5.4121 \\
Observations & $(2.835)$ & $(3.432)$ & $(3.780)$ & $(8.922)$ & $(8.422)$ & $(4.233)$ \\
R-squared & 1,261 & 896 & 777 & 576 & 418 & 280 \\
Robust stanc & 0.056 & 0.050 & 0.054 &. &. & 0.133 \\
\hline
\end{tabular}

Robust standard errors in parentheses, ${ }^{* * *} \mathrm{p}<0.01, * * \mathrm{p}<0.05,{ }^{*} \mathrm{p}<0.10$

Scientific Disciplines, Region and Year dummies included. " $D$ " is the treatment variable, " $X$ " is the forcing variable (relative standardized ranking) and " $D_{-} X$ " is the interaction term.

Source: Authors' elaboration

Table 6 - Treatment Effects on Publications and Citations, Non-parametric estimates

\begin{tabular}{lcccccc}
\hline & $(1)$ & $(2)$ & $(3)$ & $(4)$ & $(5)$ & $(6)$ \\
\hline Publications & $\mathrm{h}=$ global & $\mathrm{h}=1.87$ & $\mathrm{~h}=1.62$ & $\mathrm{~h}^{*}=1.37$ & $\mathrm{~h}=1.12$ & $\mathrm{~h}=0.87$ \\
$\mathrm{D}$ & $3.4666^{* * *}$ & $4.1736^{* * * *}$ & $4.7345^{* *}$ & $5.5982^{* *}$ & $7.2836^{*}$ & 14.0306 \\
& $(1.271)$ & $(1.616)$ & $(1.959)$ & $(2.593)$ & $(3.984)$ & $(11.747)$ \\
Observations & 3,101 & 2,634 & 2,272 & 1,942 & 1,632 & 1,208 \\
\hline Citations & $\mathrm{h}=$ global & $\mathrm{h}=1.38$ & $\mathrm{~h}=1.13$ & $\mathrm{~h}^{*}=0.88$ & $\mathrm{~h}=0.63$ & $\mathrm{~h}=0.38$ \\
D & -1.7525 & -4.2902 & -18.8162 & 7.9279 & -0.2571 & 6.5890 \\
& $(2.569)$ & $(8.874)$ & $(45.858)$ & $(16.158)$ & $(3.746)$ & $(12.435)$ \\
\hline
\end{tabular}




\begin{tabular}{lcccccc}
\hline Observations & 1,261 & 896 & 777 & 576 & 418 & 280 \\
\hline$* * * \mathrm{p}<0.01, * * \mathrm{p}<0.05, * \mathrm{p}<0.10$ \\
" $D$ ” $i$ is the treatment variable. All control variables included. \\
\hline
\end{tabular}

Source: Authors' elaboration

Summing up, our results clearly indicate that FONDECYT successfully contributed to increase the quantity of scientific production of the Chile's National Innovation System (NIS), but not its quality. As discussed in section 3, one would expect the grants offered by a national research fund to affect the relative rewards from research compared with other activities such as teaching and consulting. From the individual's point of view therefore, receiving a grant may induce the researcher to allocate time away from consulting towards research, or to put more effort in a given research time. In this way, a grant may stimulate research efforts and affect both quantity and quality of outputs. In the case of FONDECYT this effect is reflected in a greater number of publications, but not in higher quality. Why?

The explanation for this mixed impact should be first sought in how the specific characteristics of FONDECYT's funding process may or may not affect different research outputs. Two issues might be particularly relevant: (i) the average amount of the funding per project, and (ii) the incentive embedded in the selection and disbursement mechanisms of the program.

As pointed out in Section 2, during the evaluation period, the actual funding per project granted by FONDECYT is relatively low, especially when compared to research funding in developed countries. A problem of low per-project funding seems consistent with our results. The resources granted by FONDECYT are probably enough to support a significant increase in the volume of publications in indexed journals, but not enough to generate a significant jump in quality of these publications. In fact, while the number of publications can be increased also through relatively inexpensive activities - for instance, networking, promotion of studies at conferences and seminars and hiring of research assistants -, improving the quality of research may require much more expensive investments - such as new or renewed laboratories, data collections, field works.

In addition, the FONDECYT's funding allocation and disbursement include explicit incentive to publish more in indexed journals, but not to produce better publications. The researchers are asked to indicate in what journal they expect to publish their results and the closing of the project is somehow conditional to the submission of the manuscript to these journals. Again, the incentives potentially created by such provision seem consistent with our results. Indeed, this provision introduces a clear and specific incentive to publish more in indexed journal, but not necessarily to seek for higher quality products. One could claim that the quality incentive is embedded in the quality of the targeted journals. Even considering this, the incentives clearly seem more binding on the quantity rather than quality of publications.

\section{Conclusion}


The impact evaluation of the FONDECYT shows clear evidence of a positive and significant impact in terms of PRs' publications. Indeed, using the most conservative estimates produced by a SRD design, we find an impact of about two additional publications in the six year time window after the reception of the grant. These figures compares favorably with the results obtained for the Argentina's FONCYT (Chudnovsky et al., 2008) - about one additional publication - and the NIH postdoctoral and regular research programs (Jacob and Lefgren, 2011a, 2011b) - also of around one additional publication. So, in principle, we can conclude that the FONDECYT program had a significant impact on the scientific productivity of Chilean researchers.

However, this increase of research output's volume might have come at the cost of a lack of impact in terms of quality. Indeed, either using different RD designs or considering several additional bandwidths, we failed to find any significant evidence of an impact on research quality as measured by the average citations per publication. This finding is at odds with the results obtained by Chudnovsky et al. (2008) and Jacob and Lefgren (2011a, 2011b) for the Argentina's FONCYT and the NIH programs, where positive impacts on citations were obtained. However, this difference may be due to the fact that these two benchmark programs provided much higher funding per project than FONDECYT did during the period we consider. Therefore, the impact of these two programs on citations seems to reinforce the conclusion that the lack of impact of FONDECYT on citations could come from the relatively low funding per-project.

Before discussing any policy recommendations it is important to emphasize that because international funding and additional funding mechanisms established by the Chilean authorities were available, our results may not yield the impact of FONDECYT relative to a clean "nonsupport" situation, but the impact relative to the next-best funding option. ${ }^{40}$ However, while these additional sources of funding were available, they clearly focused on technologically applied or mission oriented research and not on the kind of basic and curiosity driven research supported by FONDECYT. So, we expect that the degree of overlap or actual competition between FONDECYT and these other sources of funding be quite small, in particular during our evaluation period. In addition, one needs to remember that these alternative funds were available for both the treated and control groups of researchers. ${ }^{41}$

Our findings on the lack of impact on research quality are certainly concerning and call for a critical review of the program. It is very likely, that the meager amount of funding provided by the program may have led to target the wrong type of research projects. Excessive risk aversion may have also led to target research projects with lower fixed costs, lower risk and, in some case, lower originality. On the top of this, the rule of project completion could have contributed to induce the researcher to submit projects that minimize the risk of failure, projects that can generate publication volume, but not as much research quality.

\footnotetext{
${ }^{40}$ This problem could be eliminated in an experimental framework. However, this type of design is not common in science policy.

${ }^{41}$ Another reason to be careful with the interpretation of our results is that the specific technique adopted for the impact estimation only captures the so-called Local Average Treatment Effect (LATE). This means that we are measuring the effects of the program on a restricted group of beneficiaries compared with a restricted group of non-beneficiaries at the threshold level.
} 
The results of this evaluation suggest that any review of FONDECYT should focus on the inclusion of specific incentives to foster the quality of scientific production. This could be done by either increasing the average size of the grant provided by the program to a figure closer to the international standards ${ }^{42}$ together with adding an ex-post reward system based on citations.

This study is certainly just a first step towards better understanding of the impacts of science policy in developing country contexts. A more comprehensive approach should also include the impacts on the scientific capabilities of the country, in particular in the progression of the researchers' academic careers, and on the formation of advanced human capital - e.g. PhD students. Furthermore, more research is also needed for a full assessment of the social returns of a program as FONDECYT. This would require considering all the program's benefits, including the potential externalities generated by the research projects, and full amount of the public and private economic resources invested in the program, both in the supported project and in the administration of the funding agency. A future evaluation of FONDECYT impact would also benefit from controlling for other characteristics of the principal researcher, research team and research project and also for alternative sources of funding. In the same direction, future extensions of this study could focus on the heterogeneity of impact for different categories of researchers and research project. Only a significantly expanded set of information that the one currently available would allow these research extensions.

\footnotetext{
${ }^{42}$ Changes in this direction have already been introduced by CONICYT.
} 


\section{Appendix I}

\section{Distribution of Publications and Citations}
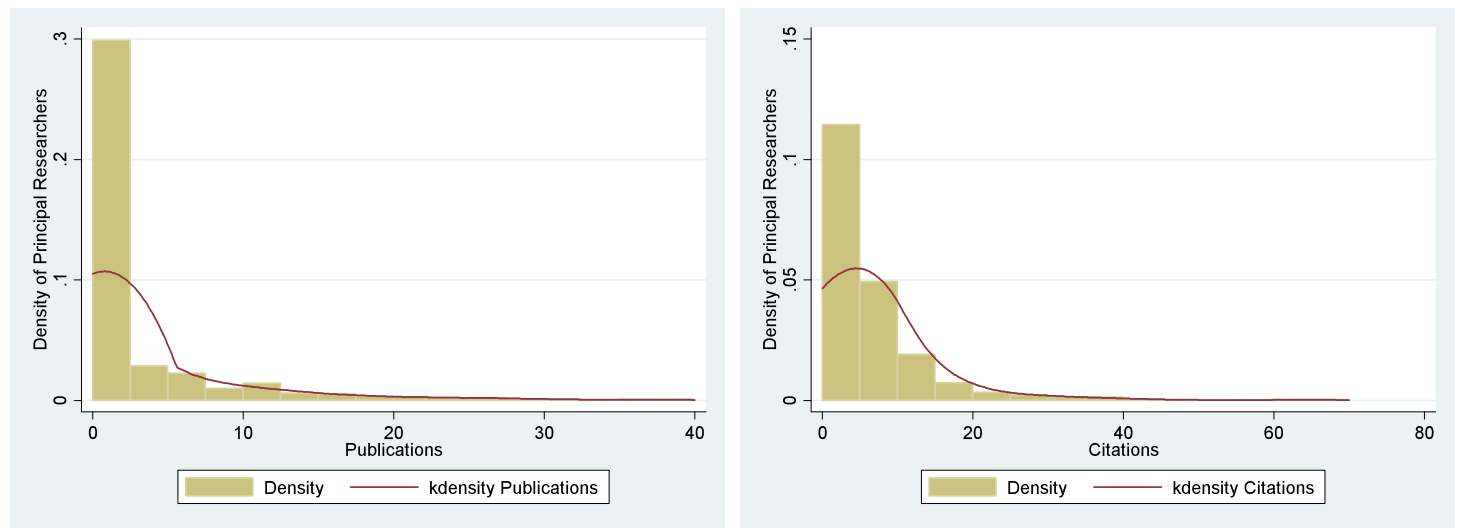

Source: Authors' elaboration

\section{Appendix II}

\section{Percentages of PRs by scientific discipline and treatment (full sample) ${ }^{43}$}

\begin{tabular}{lcc}
\hline SCIENTIFIC DISCIPLINE & GRANT $=1$ & GRANT $=0$ \\
\hline Agronomy/Zoology & $7.67 \%$ & $8.37 \%$ \\
Social Sciences & $20.99 \%$ & $27.96 \%$ \\
Natural Sciences & $30.70 \%$ & $14.75 \%$ \\
Earth Sciences & $2.91 \%$ & $3.15 \%$ \\
Engineering Sciences & $10.16 \%$ & $11.39 \%$ \\
Medical Sciences & $14.22 \%$ & $17.59 \%$ \\
Legal-Economic-Management Sciences & $6.32 \%$ & $8.86 \%$ \\
Humanities & $8.01 \%$ & $7.93 \%$ \\
\hline
\end{tabular}

43 These percentages become more balanced by discipline when restricting the sample to smaller bandwidths around the cut-off point. This applies in particular for the case of Natural Sciences. 


\section{Appendix III}

Percentages of PRs by year and treatment (full sample)

\begin{tabular}{lcc}
\hline YEAR & GRANT $=1$ & GRANT $=0$ \\
\hline 1988 & $6.43 \%$ & $14.22 \%$ \\
1989 & $9.59 \%$ & $8.15 \%$ \\
1990 & $10.61 \%$ & $14.36 \%$ \\
1991 & $9.81 \%$ & $11.39 \%$ \\
1992 & $10.16 \%$ & $10.63 \%$ \\
1993 & $10.95 \%$ & $8.64 \%$ \\
1994 & $9.03 \%$ & $9.39 \%$ \\
1995 & $13.88 \%$ & $7.58 \%$ \\
1996 & $8.80 \%$ & $7.93 \%$ \\
1997 & $10.72 \%$ & $7.71 \%$ \\
\hline
\end{tabular}

Source: Authors' elaboration

\section{Appendix IV}

Treatment Effects on Publications and Citations, Negative Binomial estimates

\begin{tabular}{lcccccc}
\hline PUBLICATIONS & $(1)$ & $(2)$ & $(3)$ & $(4)$ & $(5)$ & $(6)$ \\
\hline COEFFICIENT & All & $\mathrm{h}=1.87$ & $\mathrm{~h}=1.62$ & $\mathrm{~h} *=1.37$ & $\mathrm{~h}=1.12$ & $\mathrm{~h}=0.87$ \\
$\mathrm{D}$ & $0.5430^{* * *}$ & $0.6239^{* * *}$ & $0.6243^{* * *}$ & $0.6894 * * *$ & $0.6573 * * *$ & $0.5684 * * *$ \\
& $(0.140)$ & $(0.141)$ & $(0.145)$ & $(0.146)$ & $(0.149)$ & $(0.171)$ \\
\hline D (IV) & $0.8740^{* * *}$ & $1.1433^{* * *}$ & $1.1063 * * *$ & $1.2895 * * *$ & $1.5325 * * *$ & $1.9369 *$ \\
& $(0.321)$ & $(0.356)$ & $(0.403)$ & $(0.478)$ & $(0.590)$ & $(1.045)$ \\
Observations & 3,101 & 2,634 & 2,272 & 1,942 & 1,632 & 1,208 \\
\hline & & & & & & \\
\hline CITATIONS & $(1)$ & $(2)$ & $(3)$ & $(4)$ & $(5)$ & $(6)$ \\
\hline COEFFICIENT & $\mathrm{All}$ & $\mathrm{h}=1.38$ & $\mathrm{~h}=1.13$ & $\mathrm{~h} *=0.88$ & $\mathrm{~h}=0.63$ & $\mathrm{~h}=0.38$ \\
D & -0.1285 & -0.0968 & -0.1291 & -0.1480 & -0.0564 & -0.1390 \\
& $(0.105)$ & $(0.109)$ & $(0.110)$ & $(0.120)$ & $(0.144)$ & $(0.167)$
\end{tabular}




\begin{tabular}{lcccccc} 
D (IV) & -0.2281 & -0.0935 & -0.4056 & -2.1350 & 0.9075 & -0.7100 \\
& $(0.333)$ & $(0.556)$ & $(0.748)$ & $(1.993)$ & $(1.982)$ & $(1.026)$ \\
Observations & 1,261 & 896 & 777 & 576 & 418 & 280 \\
\hline
\end{tabular}

Robust standard errors in parentheses, ${ }^{* * *} \mathrm{p}<0.01,{ }^{* *} \mathrm{p}<0.05,{ }^{*} \mathrm{p}<0.10$

All control variables included. " $D$ " is the treatment variable.

Source: Authors' elaboration

\section{Appendix V}

Dependence of the estimated effects on Publications on bandwidth selection

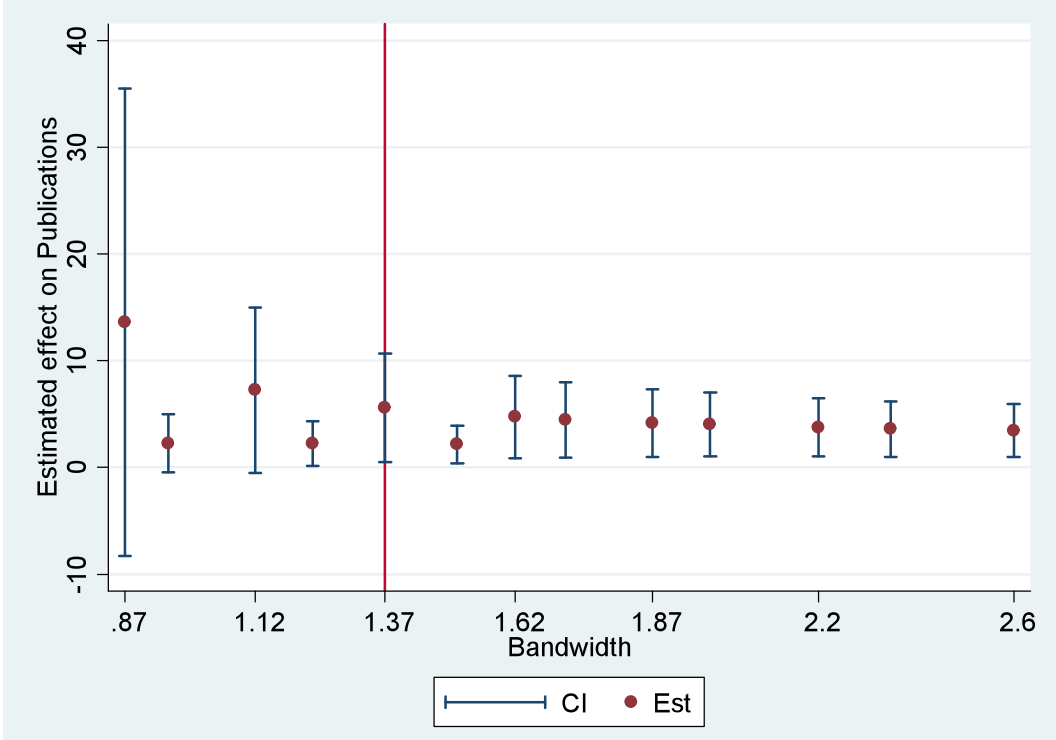

* The vertical line indicates the "Optimal bandwidth".

Source: Authors' elaboration

Dependence of the estimated effects on Citations on bandwidth selection 


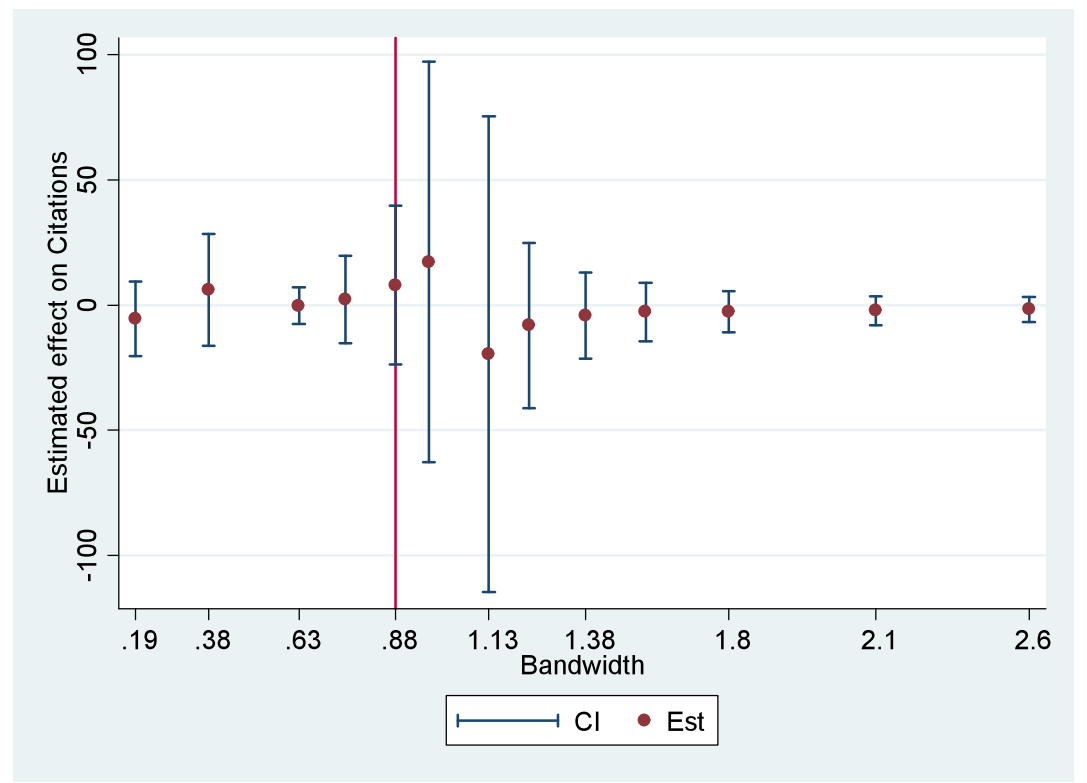

* The vertical line indicates the "Optimal bandwidth".

Source: Authors' elaboration

\section{References}

Amin, M. and Mabe, M. (2000) "Impact Factors: Use and Abuse", Perspectives in Publishing No 1.

Angrist, J.D. and Lavy, V. (1999) 'Using Maimonides' Rule to Estimate the Effect of Class Size on Scholastic Achievement", Quarterly Journal of Economics 114(2):533-575.

Arora, A. and Gambardella, A. (2005) "The Impact of NSF Support for Basic Research in Economics", Annales d'Economie et de Statistique No. 79/80, pp.91-117.

Arrow, K. (1962) "Economics Welfare and the Allocation of Resources for Invention", in R. Nelson (ed.), The Rate and Direction of Inventive Activity, Princeton University Press, pp. 164-181.

Benavente, J.M. and Crespi, G. (1996) "The Chilean national system of innovation", Estudios de Economía, University of Chile, Department of Economics, vol. 23(2 Year 19):223-254.

Black, S. (1999) "Do Better Schools Matter? Parental Valuation of Elementary Education, Quarterly Journal of Economics 114(2):577-599.

Buchmueller, T., Dominitz, J. and Hansen, L. (1999) "Graduate Training and the Early Career Productivity of PhD Economists", Economics of Education Review 14, pp. 65-77.

Cameron, B. (2005) "Trends in the Usage of ISI Bibliometric Data: Uses, Abuses, and Implications", Librarian and Staff Publications, Paper 3. 
Chudnovsky D., López, A., Rossi, M. and Ubfal, D. (2008) "Money for Science? The Impact of Research Grants on Academic Output", Fiscal Studies 29(1):75-87.

Codner, D. (2011) “Alcance, resultados e impactos del FONCYT entre 2006 y 2010”, in Investigación Científica e Innovación Tecnológica en Argentina: impacto de los fondos de la agencia nacional de promoción científica y tecnológica. Porta, F. and Lugones, G., Universidad Nacional de Quilmes Editorial.

Crespi, G. and Geuna, A. (2004) "The Productivity of Science", Brighton: SPRU Report prepared for the Office of Science and Technology (OST), Department of Trade and Industry (DTI), UK.

Crespi, G. and Geuna, A. (2005) "Modeling and Measuring Scientific Production: Results for a Panel of OECD Countries", SPRU Electronic Working Paper Series, No. 133, The Freeman Centre, University of Sussex.

Dasgupta, P. and David, P. (1994) "Toward a New Economics of Science", Research Policy 23(5):487-521.

Debackere, K. and Glänzel, W. (2004) "Using a Bibliometric Approach to Support Research Policy Decisions: The Case of The Flemish BOF-key", Scientometrics 59(2):253-276.

Diamond, A. (1986) "The Life-Cycle Research Productivity of Mathematicians and Scientists", Journal of Gerontology 41(4):520-525.

DiNardo, J., and Lee, D.S. (2004) "Economic Impacts of New Unionization on Private Sector Employers: 1984-2001”, Quarterly Journal of Economics 119(4):1383-1441.

Fuji, D., Imbens, G.W. and Kalyanaraman, K. (2009) "Notes for Matlab and Stata Regression Discontinuity Software", Manuscript, Harvard University.

Gambardella, A. (2001) "Economic Tools and Methodologies for the Design of Research Programmes in the Socio-economic Field", Expert's Evaluation prepared for the DG XII. Pisa, Sant'Anna School of Advanced Studies.

Gonzalez-Brambila, C. and Veloso, F.M. (2007) "The determinants of research output and impact: A study of Mexican researchers", Research Policy 36(7):1035-1051.

Hahn, J., Todd, P. and Van der Klaauw, W. (2001) "Identification and Estimation of Treatment Effects with a Regression Discontinuity Design", Econometrica 69(1):201-209.

IDB (2006), IDB's Science and Technology Programs: An Evaluation of the Technology Development Funds (TDF) and Competitive Research Grants (CRG), mineo, Washington DC.

Imbens, G.W. and Kalyanaraman, K. (2009) "Optimal Bandwidth Choice for the Regression Discontinuity Estimator”, NBER Working Paper No. 14726.

Imbens, G.W. and Wooldridge, J.M. (2009) "Recent Developments in the Econometrics of Program Evaluation", Journal of Economic Literature 47(1): 5-86.

Imbens, G. and Lemieux, T. (2008) "Regression Discontinuity Designs: A Guide to Practice", Journal of Econometrics 142(2): 615-635.

Jacob, B.A. and Lefgren, L. (2011a) "The impact of NIH postdoctoral training grants on scientific producitivity", Research Policy 40(6):864-874. 
Jacob, B.A. and Lefgren, L. (2011b) "The impact of research grant funding on scientific productivity”, Journal of Public Economics 95(9-10):1168-1177.

Jaffe, A. (2002) "Building Program Evaluation into the Design of Public Research Support Programs", Oxford Review of Economic Policy 18(1):22-34.

Lach, S. (2002) "Do R\&D Subsidies Stimulate or Displace Private R\&D? Evidence from Israel", Journal of Industrial Economics 50(4):369-390.

Lalive, R. (2008) "How do extended benefits affect unemployment duration? A regression discontinuity approach", Journal of Econometrics 142(2):785-806.

Lee, D.S. and Lemieux, T. (2009) "Regression Discontinuity Designs In Economics", Journal of Economic Literature 48(2):281-355.

Long, J.S. (editor) (2001) From Scarcity to Visibility: Gender Differences in the Careers of Doctoral Scientists and Engineers. Washington, D.C.: National Academy Press. Chapter 6: "The Academic Career".

Lundvall, B. (1992) National systems of innovation, Pinter Publishers, London.

McCrary, J. (2008) "Manipulation of the Running Variable in the Regression Discontinuity Design: a Density Test", Journal of Econometrics 142(2): 698-714.

Mollas-Gallart, J. and Salter, A. (2002) "Diversidad y Excelencia: Consideraciones sobre Política Científica”, The IPTS Report, n. 66, julio.

Mohnen, P. and Roller, L-H. (2005) "Complementarities in innovation policy", European Economic Review 49(6):1431-1450.

Narin F. (1976) Evaluative bibliometrics: The use of publication and citation analysis in the evaluation of scientific acitivity, Cherry Hill, NJ: Computer Horizons.

Nelson, R. (1959) “The Simple Economics of Basic Scientific Research", Journal of Political Economy 67(3):297-306.

Patel, P. and Pavitt, K. (2000) "National Systems of Innovation under Strain: The Internationalization of Corporate R \& D" in R. Barrell, G. Mason and M. O'Mahoney (eds.) Productivity, Innovation and Economic Performance, Cambridge UP.

Pavitt, K. (2001) "Public policies to support basic research: What can the rest of the world learn from US theory and practice? (And what they should not learn)", Industrial and Corporate Change 10(3):761-79.

Rosenberg, N. (1992) "Scientific Instrumentation and University Research", Research Policy 21(4):381-390.

Salter, A. and Martin, B. (2001) "The Economic Benefit of Publicly Funded Basic Research: A Critical Review”, Research Policy 30(3):509-532.

Scherer, F. and Harhoff, D. (2000) "Technology policy for a world of skew-distributed outcomes", Research Policy 29(4-5):559-566.

Stephan, P. (1996) "The Economics of Science", Journal of Economic Literature 34(3):1199-1235.

Stephan, P. (2010) "The Economics of Science", in Handbook on the Economics of Innovation. Hall, B. and N. Rosemberg, North Holland. 
Thistlethwaite, D. and Campbell, D. (1960) "Regression-Discontinuity Analysis: An Alternative to the Exp-post Facto Experiment", Journal of Educational Psychology 51(6):309-317.

Turner, L. and Mairesse, J. (2005) "Productivity differences across individuals in public research: an econometric study of French physicists' publications and citations (1980-1997)". Forthcoming in Annales d'Economie et de Statistiques.

Ubfal, D. and Maffioli, A. (2011) "The impact of funding on research collaboration: Evidence from a developing country", Research Policy 40(9):1269-1279.

Urquiola, M. And Verhoogen, E. (2009) "Class-Size Caps, Sorting, and the RegressionDiscontinuity Design", The American Economic Review 99(1):179-215.

Van Der Klaauw, W. (2002) "Estimating the Effect of Financial Aid Offers on College Enrollment: A Regression-Discontinuity Approach”, International Economic Review 43(4):1249-1287. 